\title{
Review of experimental studies of secondary ice production
}

\author{
Alexei Korolev ${ }^{1}$ and Thomas Leisner ${ }^{2,3}$ \\ ${ }^{1}$ Environment and Climate Change Canada, Toronto, Canada \\ ${ }^{2}$ Institute of Meteorology and Climate Research, Karlsruhe Institute of Technology, Karlsruhe, Germany \\ ${ }^{3}$ Institut für Umweltphysik, University of Heidelberg, Heidelberg, Germany
}

Correspondence: Alexei Korolev (alexei.korolev@ canada.ca)

Received: 2 June 2020 - Discussion started: 22 June 2020

Revised: 26 August 2020 - Accepted: 27 August 2020 - Published: 19 October 2020

\begin{abstract}
Secondary ice production (SIP) plays a key role in the formation of ice particles in tropospheric clouds. Future improvement of the accuracy of weather prediction and climate models relies on a proper description of SIP in numerical simulations. For now, laboratory studies remain a primary tool for developing physically based parameterizations for cloud modeling. Over the past 7 decades, six different SIPidentifying mechanisms have emerged: (1) shattering during droplet freezing, (2) the rime-splintering (Hallett-Mossop) process, (3) fragmentation due to ice-ice collision, (4) ice particle fragmentation due to thermal shock, (5) fragmentation of sublimating ice, and (6) activation of ice-nucleating particles in transient supersaturation around freezing drops. This work presents a critical review of the laboratory studies related to secondary ice production. While some of the six mechanisms have received little research attention, for others contradictory results have been obtained by different research groups. Unfortunately, despite vast investigative efforts, the lack of consistency and the gaps in the accumulated knowledge hinder the development of quantitative descriptions of any of the six SIP mechanisms. The present work aims to identify gaps in our knowledge of SIP as well as to stimulate further laboratory studies focused on obtaining a quantitative description of efficiencies for each SIP mechanism.
\end{abstract}

\section{Introduction}

Secondary ice production (SIP) is defined here as the formation of atmospheric ice as a result of processes involving preexisting ice particles, in contrast to primary ice production, which commences by the nucleation of ice either homoge- neously in strongly supercooled droplets or heterogeneously on the surface of ice-nucleating particles (INPs) (e.g., Kanji et al., 2017). SIP is one of the fundamental cloud microphysical processes, recognized as a major contributor to the observed concentration of ice particles at temperatures warmer than the homogeneous freezing temperature.

Even though SIP was observed in early laboratory experiments (e.g., Dudetski and Sidorov, 1911; Findeisen, 1940; Findeisen and Findeisen, 1943; Brewer and Palmer, 1949; Malkina and Zak, 1952; Puzanov and Accuratov, 1952; Schaefer, 1952; Bigg, 1957), the geophysical significance of SIP was recognized only after the beginning of regular airborne studies of cloud microstructure in different geographical regions (e.g., Koenig, 1963, 1965; Hobbs, 1969; Mossop, 1970, 1985a; Mossop et al., 1964, 1972; Ono, 1971, 1972; Hallett et al., 1978; Hobbs and Rangno, 1985, 1989; Beard, 1992; and many others). A systematically observed enhancement of the number concentration of cloud ice particles over the concentration of INPs in the same air mass suggested a need for the provision of an explanation of the physical processes underlying this discrepancy.

From the late 1950 s to early 1970s, six possible mechanisms were proposed explaining the secondary production of ice crystals. However, since then, limited progress has been made in understanding of how each of those mechanisms contribute to the ice particle concentrations and what the necessary and sufficient conditions are for initiating each of these mechanisms. This situation is complicated by the fact that numerical cloud models tend to focus on only one of the six possible mechanisms, namely the rime-splintering (Hallett-Mossop) process, whereas other mechanisms have been disregarded. 
Beyond recent reviews on in situ studies of ice multiplication (e.g., Cantrell and Heymsfield, 2005; Field et al., 2017), little attention has been devoted to exploring the details of laboratory studies on SIP mechanisms. To bridge this gap, this paper provides an extended review of experimental works on SIP. Laboratory studies with reproducible and controlled environments are the basic means of examining physical processes underlying each SIP mechanism, as well as quantifying the rates of secondary ice production, and identifying necessary and sufficient conditions required for initiation of these mechanisms. Without this knowledge, a development of the physically based parameterizations of SIP in weather prediction and climate simulations is not feasible. Due to their coarse spatial and temporal resolution, in situ airborne (by nature Eulerian) observations should be used for validation and feedback of laboratory and theoretical SIP studies, rather than serve as a primary tool for developing parameterizations for numerical simulations.

This work is an overview of the current knowledge of SIP obtained from laboratory studies. In situ observations and theoretical studies of SIP are mentioned here occasionally, though many of them remained outside the frame of this review. For the sake of thoroughness, experimental studies of the effects of artificial ice particle fragmentation during sampling were included in this review as well.

This review aims to provide navigation for future experimental works that seek to enhance our understanding of SIP mechanisms.

The present paper describes laboratory studies of the following SIP mechanisms: the fragmentation of droplets during their freezing (Sect. 2), rime splintering (Sect. 3), fragmentation due to collision of ice particles with each other (Sect. 4), ice particle fragmentation due to thermal shock caused by freezing droplets on their surface (Sect. 5), fragmentation of sublimating ice particles (Sect. 6), and activation of ice-nucleating particles in transient supersaturation around freezing drops (Sect. 7). Section 8 describes experimental studies that look at spurious enhancement of ice concentration during in situ measurements, which can be confused with SIP. The concluding remarks are presented in Sect. 9.

The authors would like to acknowledge the length disproportions between the aforementioned sections. Section 2 has the biggest volume, which is a reflection of the large amount on knowledge accumulated on different aspects of water freezing directly linked to the secondary ice formation during droplet freezing. The rest of the sections are smaller in size due to fewer laboratory experiments related to them. These disproportions will be discussed in more detail in Sect. 9.1.

\section{Fragmentation of freezing drops}

Historically, the first mechanism proposed to explain SIP was the fragmentation of freezing droplets (e.g., Langham

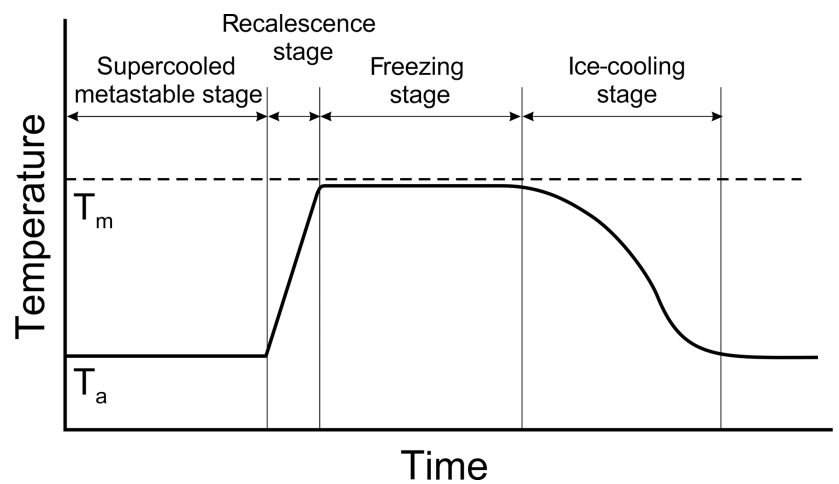

Figure 1. A conceptual diagram of temperature changes during the freezing of a supercooled droplet. Here $T_{\mathrm{m}}$ and $T_{\mathrm{a}}$ are the melting and environmental temperatures, respectively. During the metastable stage, droplet temperature is assumed to be equal to the air temperature $T_{\mathrm{a}}$.

and Mason, 1958; Mason and Maybank, 1960; Kachurin and Bekryaev, 1960; Muchnik and Rudko, 1961). During the freezing process of a cloud droplet, liquid water may be trapped inside a growing ice shell formed around the droplet. The expansion of ice during further freezing results in an increase in pressure inside the ice shell. If the pressure exceeds a critical point, the ice shell may crack or shatter to relieve the internal pressure. The ice fragments that result from droplet cracking or shattering will serve as secondary ice. In addition, gases dissolved in the droplet might be released during the pressure-drop events. Gas bubbles may burst upon freezing at the colder droplet surface, resulting in a second source of fresh small ice fragments.

One of the necessary conditions for SIP during droplet freezing is the creation of a closed ice shell and subsequent inward freezing. Therefore, depending on the way in which the droplet freezes, it may or may not generate secondary ice. Hence, our consideration begins with a review of studies on the process of droplet freezing.

\subsection{Freezing stages of a supercooled drop}

The process of freezing of a supercooled droplet can be divided into two main stages. The first stage is a process that involves negligible heat exchange with the surrounding air. During this period, a dendritic ice network (slushy ice) forms through the liquid phase, releasing latent heat and heating up the liquid toward the melting point. This stage is usually referred to as the "fast" or "recalescence" stage. The second stage is quasi-isothermal and determined by the freezing of the remaining liquid water. The heat transfer during this stage is directed to the air-droplet interface. The second stage is usually called the "slow" or "freezing" stage. After freezing is complete, the temperature of the frozen droplet gradually decreases towards the ambient temperature to attain a thermal equilibrium. 
A conceptual diagram of the temperature changes during the freezing of a supercooled droplet is shown in Fig. 1. Documented temperature changes during the freezing of supercooled liquid drops can be found in e.g., Mason and Maybank (1960), Muchnik and Rudko (1961), Pena et al. (1969), Bauerecker et al. (2008), and Tavakoli et al. (2015).

\subsection{Freezing fraction}

The amount of frozen liquid water $\Delta m$ during the recalescence stage can be estimated from a simplified equation of heat balance:

$\Delta m L_{m}=\Delta m c_{\mathrm{i}} \Delta T+(m-\Delta m) c_{\mathrm{W}} \Delta T+\Delta Q$,

where $m$ is the droplet mass; $\Delta T=T_{\mathrm{m}}-T_{\mathrm{a}}$ is the droplet supercooling; $T_{\mathrm{m}}$ and $T_{\mathrm{a}}$ are the melting point and air temperatures, respectively; $L_{m}$ is the latent heat of freezing; $c_{\mathrm{i}}$, and $c_{\mathrm{W}}$ are the specific heat of ice and liquid water; $\Delta Q$ is the heat loss due to thermal exchange with the environment. A description of variables is provided in Appendix A. Equation (1) assumes that the droplet nucleating temperature $T_{\mathrm{n}}=T_{\mathrm{a}}$.

After neglecting $\Delta Q$ and $\left(c_{\mathrm{i}}-c_{\mathrm{W}}\right) \Delta m \Delta T$, Eq. (1) yields an approximation of the fraction of water $\mu=\Delta m / m$ frozen during the recalescence stage as

$\mu=\frac{c_{\mathrm{w}} \Delta T}{L_{m}}$.

Down to a temperature of $-30^{\circ} \mathrm{C}$, Eq. (2) is in very good agreement with an exact solution of Eq. (1) with $T$ dependent material properties. Using a nuclear magnetic resonance technique, Hindmarsh et al. (2005) measured a fraction of frozen water formed in a supercooled $2 \mathrm{~mm}$ diameter drop during the recalescence stage of freezing. They found the experimentally measured $\mu$ is in good agreement with that predicted by Eq. (2) (Fig. 2).

Equation (2) yields that only a relatively small fraction of water freezes during the first stage. Thus, at -4 and $-20^{\circ} \mathrm{C}$, the frozen fraction of water will be approximately $5 \%$ and $23 \%$, respectively.

\subsection{Droplet freezing time}

The timescale of the recalescence stage can be assessed as (Macklin and Payne, 1967)

$t_{1}=D / G(\Delta T)$,

where $D$ is the droplet diameter, and $G(\Delta T)$ is the rate of ice growth at water supercooling $\Delta T$. The growth rate $G(\Delta T)$ was studied by many research groups (e.g., Lindenmeyer et al., 1959; Hallett, 1964; Pruppacher, 1967a; Feuillebois et al., 1995; Shibkov et al., 2003, 2005; and others). It was found that the velocity of ice growth along the $c$ axis, $G_{c}$, is considerably smaller than that along the $a$ axis, $G_{a}$ (e.g., Macklin

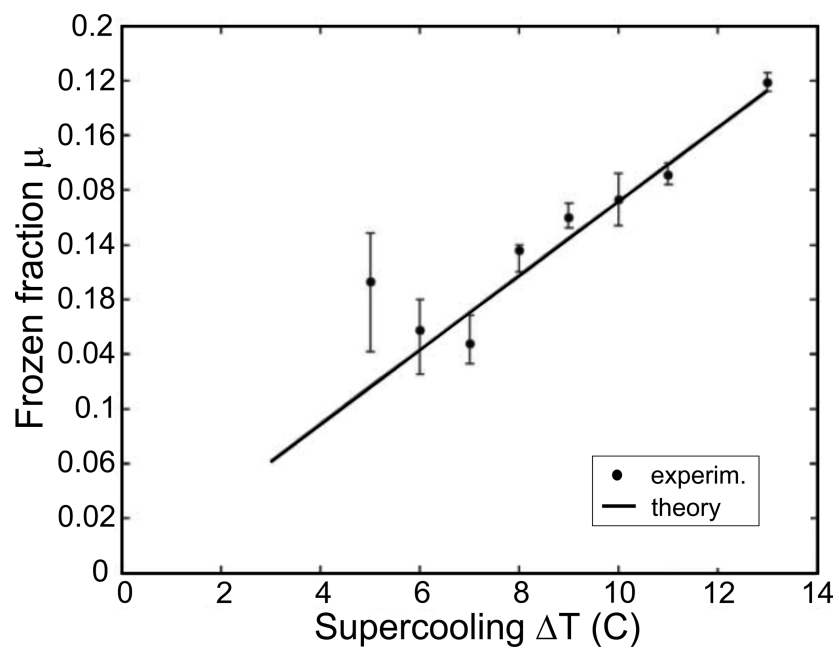

Figure 2. A frozen fraction of water $\mu$ formed in a $2 \mathrm{~mm}$ diameter drops during the recalescence stage versus temperature. The experimentally measured $\mu$ is in good agreement with that theoretically predicted by Eq. (2) (adapted from Hindmarsh et al., 2005).

and Ryan, 1968). The velocity of freely growing ice is determined as $G=\left(G_{a}^{2}+G_{c}^{2}\right)^{1 / 2}$. The summary of studies of the velocity of freely growing ice as a function of $\Delta T$ is shown in Fig. 3.

Following Fig. 3 and Eq. (3), at $T_{\mathrm{a}}=-4$ and $-20^{\circ} \mathrm{C}$ the recalescence time $t_{1}$ for droplets with $D=20 \mu \mathrm{m}$ will be approximately $5 \mathrm{~ms}$ and $5 \mu \mathrm{s}$, respectively - and for droplets with $D=2 \mathrm{~mm}, 0.5 \mathrm{~s}$ and $5 \mathrm{~ms}$, respectively.

During the freezing stage, droplets are cooling due to the thermal exchange with the ambient environment, and thus, the remaining liquid water gradually freezes. The second stage is quasi-isothermal, and it is approximately 100 1000 times slower than the first stage. According to Pruppacher and Klett (1997), the time of the second stage of the droplet freezing inward can be estimated as

$$
t_{2}=\frac{\rho_{\mathrm{w}} L_{m} D^{2}\left(1-\frac{\Delta T c_{\mathrm{w}}}{L_{m}}\right)}{12 f \Delta T\left(K_{\mathrm{a}}+L_{\mathrm{s}} D_{\mathrm{v}}\left(\overline{\left.\frac{\mathrm{d} \rho_{\mathrm{v}}}{\mathrm{d} T}\right)_{\mathrm{sa}, \mathrm{i}}}\right)\right.},
$$

where $\rho_{\mathrm{w}}$ is the liquid water density; $f$ is the ventilation coefficient; $D_{\mathrm{v}}$ is the water vapor diffusion coefficient; $K_{\mathrm{a}}$ is the thermal conductivity of the air; $L_{\mathrm{S}}$ is the latent heat of ice sublimation; $\left(\overline{\frac{d}{d} \rho_{\mathrm{v}}}\right)_{\text {sat, } \mathrm{i}}$ is the mean slope of the ice saturation vapor density curve over the interval from $T_{0}$ to $T_{\mathrm{m}}$. The ventilation coefficient $f$ describes the acceleration of droplet freezing from forced (due to the velocity between droplet and gas) and free (due to the temperature difference between droplet and gas) convection as compared to stagnant air $(f=1)$. For drizzle-sized droplets falling freely in the air, $f$ will typically assume values between 2 and 4 .

Following Eq. (4) at $T_{\mathrm{a}}=-4$ and $-20^{\circ} \mathrm{C}$, the freezing time $t_{2}$ for droplets with $D=20 \mu \mathrm{m}$ will be approximately 


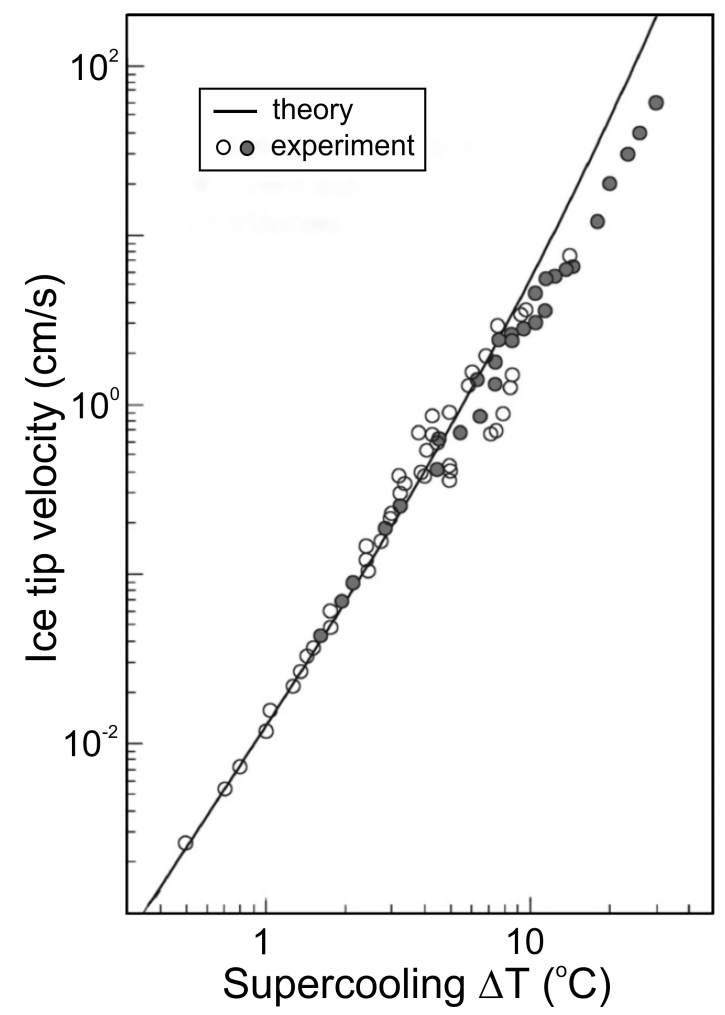

Figure 3. Summary of the measured velocity of freely growing ice as a function of supercooling measured by Lindenmeyer et al. (1959), Hallett (1964), Pruppacher (1967a), Kallungal and Barduhn (1977), Furukawa and Shimada (1993), and Feuillebois et al. (1995); Ohsaka and Trinh (1998) (open circles); and Shibkov et al. (2003) (solid circles). The theoretical curve is based on Langer and Müller-Krumbhaar (1978) results. Adapted from Shibkov et al. (2003).

70 and $11 \mathrm{~ms}-$ and for droplets with $D=2 \mathrm{~mm}, 80 \mathrm{~s}$ and $13 \mathrm{~s}$, respectively.

Since $t_{2} \gg t_{1}$ the droplet freezing time is determined by the duration of the second stage. Experimentally, the freezing time was studied by Muchnik and Rudko (1962), Murray and List (1972), and Hindmarsh et al. (2003).

It should be noted that there is a good wealth of theoretical studies on the freezing time $t_{2}$ (e.g., Macklin and Payne, 1967; King, 1975; Gupta and Arora, 1992; Feuillebois et al., 1995; Tabakova et al., 2010). However, Eq. (4) (Pruppacher and Klett, 1997) provides a reasonably accurate assessment of $t_{2}$, which is in good agreement with experimental measurements.

\subsection{Crystalline structure of ice}

The way in which ice crystals grow through the freezing droplet during the recalescence stage is of great importance for SIP for two reasons. First it affects the formation of the ice shell, and second it impacts the spatial morphology of ice and liquid regions inside the freezing droplet. The mor- phology of ice formation during water freezing was explored by Kumai and Itagaki (1953), Hallett (1960, 1964), Macklin and Ryan (1965, 1966), Pruppacher (1967a, b), Furukawa and Shimada (1993), Ohsaka and Trinh (1998), Shibkov et al. $(2003,2005)$. It was found that the shape of the ice crystals depends on the water supercooling $\Delta T$. At low supercooling $\left(1^{\circ} \mathrm{C}<\Delta T<3{ }^{\circ} \mathrm{C}\right)$, ice crystals appear as stellar dendrites or dendritic sheets growing parallel to the basal plane. With the increase in supercooling, ice crystals start splitting, causing a formation of three-dimensional complex structures (e.g., Pruppacher, 1967a, b; Shibkov et al., 2003). Splitting leads to so-called "nonrational" growth, i.e., growth that cannot be explained by rational crystallographic indices. Hallett (1964) and Macklin and Ryan $(1965,1966)$ suggested that this nonrational growth is explained by the hopper structure of ice crystal growth. One of the important findings of studies on water freezing is that the density of the ice mesh increases with the decrease in temperature, whereas the typical size of the ice crystals perpendicular to the $a$ axis becomes smaller. These transformations of ice crystals with temperature can be clearly seen in Fig. 4. The shape of the ice crystals and the density of their network have a direct impact on the size and the number of isolated water pockets formed during freezing as well as the tensile stress that is required to rupture the droplet.

Regardless of the visual randomness of crystals growing through supercooled water, the nonrational structures may compose single crystals after the droplet freezing is completed (Macklin and Ryan, 1965, 1966). Hallett (1963, 1964), Magono and Aburakawa (1969), Aufdermaur and Mays (1965), and Pitter and Pruppacher (1973) studied the formation of monocrystalline and polycrystalline droplets during droplet freezing. They all found that droplet freezing as a single crystal critically depends on the droplet size, supercooling of the droplet before freezing, and the thermal conductivity of the medium, into which the latent heat of freezing is dissipated. As it will be discussed below, droplet fragmentation during freezing and secondary ice production depend on whether droplets freeze as single crystals or polycrystals.

The average critical radius of a droplet frozen as monocrystalline decreases with the increase in supercooling $\Delta T$ (Fig. 5), and it can be parameterized as (Pitter and Pruppacher, 1973)

$r_{\mathrm{c}}=\left(\frac{a}{\Delta T K^{b}}\right)^{3}$,

where $K$ is the thermal conductivity of the medium surrounding the droplet; $a=23 ; b=1 / 8$. Equation (5) suggests that the lower the heat conductivity of the medium surrounding a drop of a given size, the larger the supercooling that can be reached when a droplet freezes as a monocrystal. Another important outcome from Eq. (5) is that for the same $\Delta T$ due to a lower value of $K$ for the air compared to ice, droplets nucleated by dust or minuscule ice crystals will have a larger 

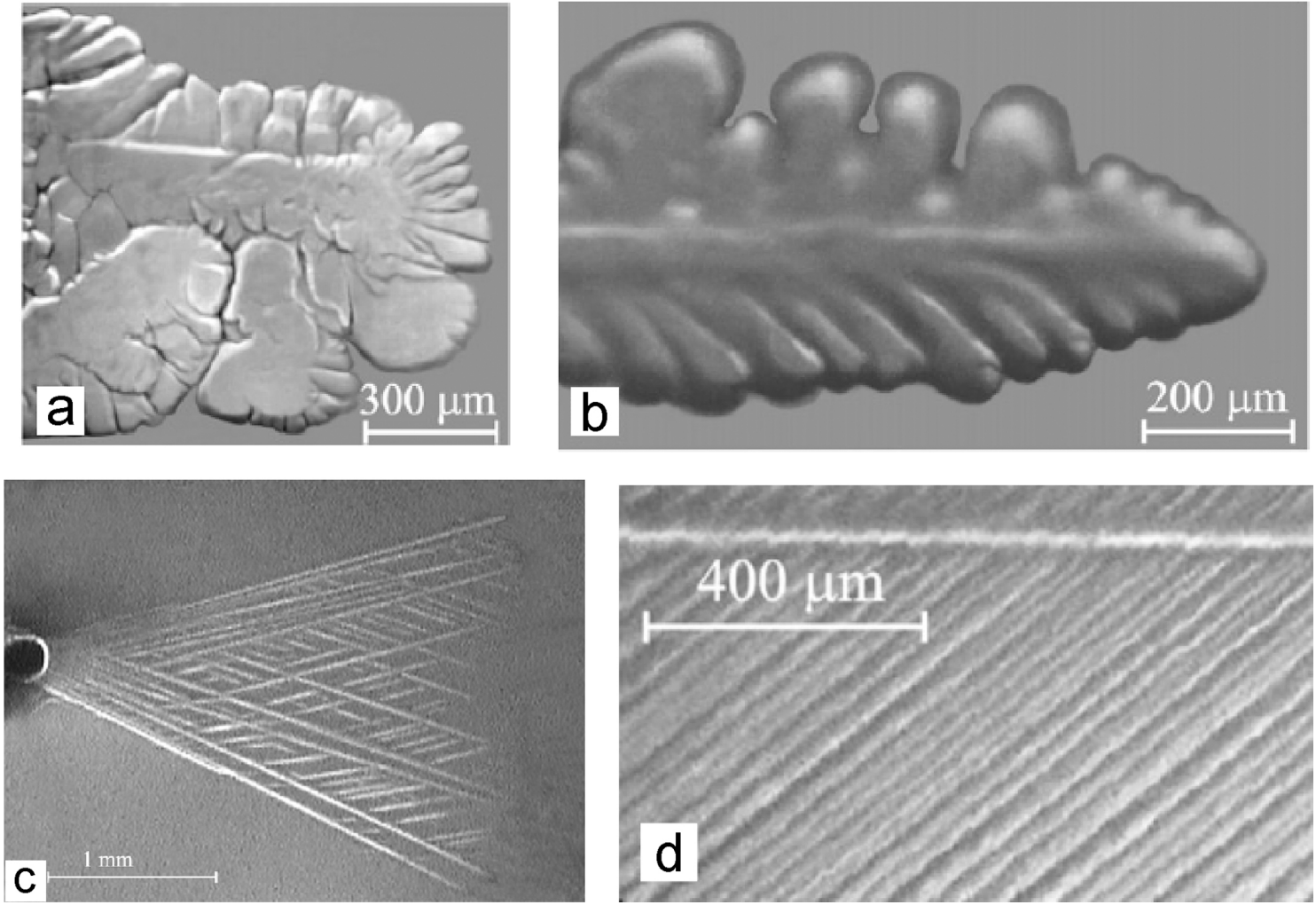

Figure 4. The morphology of ice crystal habits freely growing in pure water, supercooling at (a) $\Delta T=0.3^{\circ} \mathrm{C}$, dense brunching structure; (b) $\Delta T=1.5^{\circ} \mathrm{C}$, developed dendrite; (c) $\Delta T=4.1^{\circ} \mathrm{C}$, needle-like crystals; (d) $\Delta T=14.5^{\circ} \mathrm{C}$, compact needle mesh (adapted from Shibkov et al., 2003).

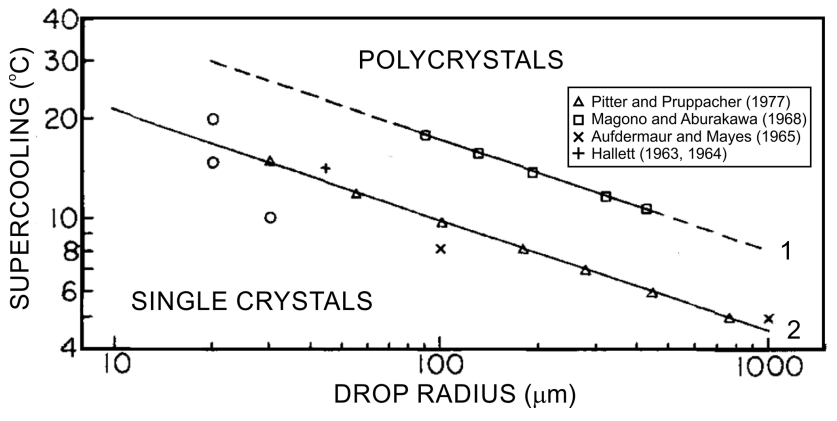

Figure 5. Dependence of the polycrystallinity of frozen droplets on the average droplet size frozen as single crystals and freezing temperature of droplets. (1) Droplets freely suspended in vertical airflow and nucleated by contact with clay particles. (2) Droplets frozen on the surface of large single crystals. Adapted from Pitter and Pruppacher (1973).

monocrystal freezing size than cases where droplets freeze on the surface of a large ice particle.

\subsection{Pressure inside freezing droplets}

The pressure inside freezing drops was measured by Visagie (1969) and King and Fletcher (1973). Water drops with im-

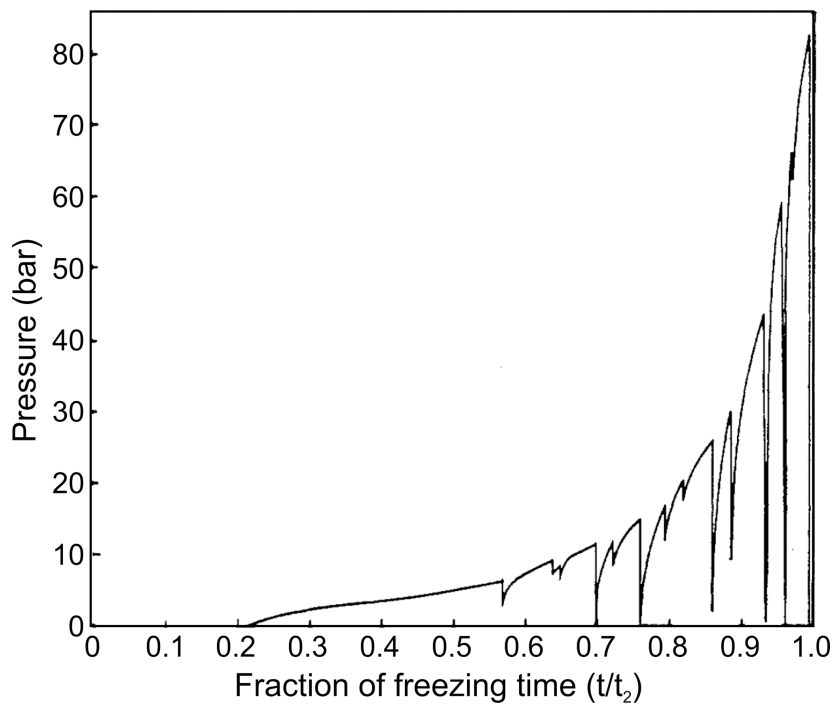

Figure 6. A time series of pressure changes inside an $11 \mathrm{~mm}$ diameter drop freezing in a bath at $-5{ }^{\circ} \mathrm{C}$ (adapted from King and Fletcher, 1973). 
mersed pressure sensors were suspended in between paraffin oil and a carbon tetrachloride bath inside a temperaturecontrolled chamber. The size of the drops varied from 7 to $12 \mathrm{~mm}$. It was found that, during freezing, the pressure inside a drop gradually built up as the shell became thicker. The pressure increase was repeatedly interrupted due to the complete or partial pressure relief brought on by cracking (Fig. 6). In this period, water extruded through a crack and froze on the surface of the drop. After the crack was sealed by frozen water, the pressure would climb back to the previous value and continue to grow. Both studies showed that the pressure increased until reaching its maximum value $P_{\max }$ near the point of complete freezing. The highest pressure, $P_{\max }=89 \mathrm{bar}$ in an $11 \mathrm{~mm}$ diameter drop at $-5^{\circ} \mathrm{C}$, was observed by King and Fletcher (1973) and 79 bar in $7 \mathrm{~mm}$ drop at $-12.8^{\circ} \mathrm{C}$ by Visagie (1969). However, no appreciable pressure growth was observed inside drops freezing at temperatures higher than $-3{ }^{\circ} \mathrm{C}$. King and Fletcher (1973) noted that about $20 \%$ of droplets contained a residual pressure of 10-20 bar at the completion of freezing.

The formation of cracks during droplet freezing was accompanied by an audible noise detected by microphone in the Visagie (1969) experiments. Loud sounds during droplet freezing and fragmentation were also reported by Dudetski and Sidorov (1911).

Visagie (1969) pointed out that besides the shell wall thickness, the cracking pressure is also a function of the temperature gradient across the ice shell (see Fig. 6 in Visagie, 1969).

King and Fletcher (1973) concluded that large droplet freezing at high temperatures will exhibit substantial viscous flow, and the smaller droplets freezing at lower temperatures will exhibit more elastic behavior and crack more often. Between these two extremes, there is probably a sizetemperature domain, in which sufficient elastic energy is stored in the shell to shatter it violently.

Both studies found that the cracking pressure increases with the increase in the thickness of the ice shell during the droplet freezing. However, the dependence of the cracking pressure versus droplet size and temperature remains unknown.

Visagie (1969) and King and Fletcher (1973) conducted experiments with overly large drops (7 to $11 \mathrm{~mm}$ ) placed in a paraffin oil and carbon tetrachloride bath. This experimental setup affects the temperature gradients in the ice shell around the freezing drops and the rate of heat exchange between the inner part of the drops and their surrounding environment. These are the critical components for the cracking behavior and the inner pressure changes. This brings up the issue of whether the obtained results are applicable to drops of smaller sizes, which typically form in natural clouds.

\subsection{Metamorphosis of droplet shape during freezing}

Visagie (1969) and King and Fletcher (1973) also documented that in addition to cracking, the release of internal pressure inside freezing drops also occurred through deformation of the shape of the ice shell. Deformation of freezing drops was reported in early observations of freezing rain and ice pellets (e.g., Bentley, 1907). However, the physical explanations of freezing drop deformation were provided almost half a century later by Dorsey (1948) and Blanchard (1951). Deformation of freezing droplets was observed by many authors in their laboratory studies (e.g., Mason and Maybank, 1960; Jonson and Hallett, 1968; Takahashi and Yamashita, 1969; Pitter and Pruppacher, 1973; Takahashi, 1975, 1976; Iwabuchi and Magono, 1975; Pruppacher and Schlamp, 1975; Uyeda and Kikuchi, 1978; Lauber et al., 2018; and many others). Furthermore, Takahashi (1975) identified four main categories of drop deformation: (a) spike (Figs. 7a and 9), (b) bulge (Fig. 7b, c), (c) split (Fig. 7c), and (d) crack (Figs. 7d and 9). During freezing, droplets may simultaneously develop a combination different types of deformations depending on the droplet diameter and temperature, e.g., spikes and cracks (Fig. 9). Sketches of a variety of different forms of bulges, cracks and spikes are available from Takahashi (1975).

Takahashi (1976) found that deformation and shattering are closely related to the crystalline structure formed during freezing. Thus, $90 \%-100 \%$ of spikes are formed if droplets are polycrystalline. The spikes usually protrude from the crystal boundary whose mechanical connection is weaker compared to monocrystalline locations. Spikes are also formed if, at the moment of nucleation, the droplet temperature is higher than the ambient temperature. However, spikes scarcely formed when the droplet was in thermal equilibrium with the environment. Takahashi (1975) found that the probability of spike formation increases with the increase in droplet size. This can be explained by the increase in the occurrence of polycrystalline frozen drops with the increase in their sizes as in Fig. 5. Takahashi (1976) and Uyeda and Kikuchi (1978) studies also showed the $c$ axis of a frozen monocrystalline droplet coincide with the $c$ axis of the seed crystal and that bulges are usually aligned with the $c$ axis.

Most experiments related to the observation of droplet deformation were performed with relatively large drops with $D>50 \mu \mathrm{m}$ and at temperatures of $T_{\mathrm{a}}>-25^{\circ} \mathrm{C}$. However, López and Ávila (2012) observed the formation of spikes and bulges on small droplets with $8 \mu \mathrm{m}<D_{\text {eff }}<30 \mu \mathrm{m}$ freezing at temperatures $-40^{\circ} \mathrm{C}$. Microphotographs of small frozen drops obtained in their experiments did not reveal cracks and splitting. The authors also did not find any evidence of shattering. However, no deformation of small droplets was observed by López and Ávila (2012) at $T=-30^{\circ} \mathrm{C}$. It is worth noting that the interpretation of López and Ávila (2012) is hindered by an absence of information about the nucleating temperature of droplets. Since the droplets were intro- 

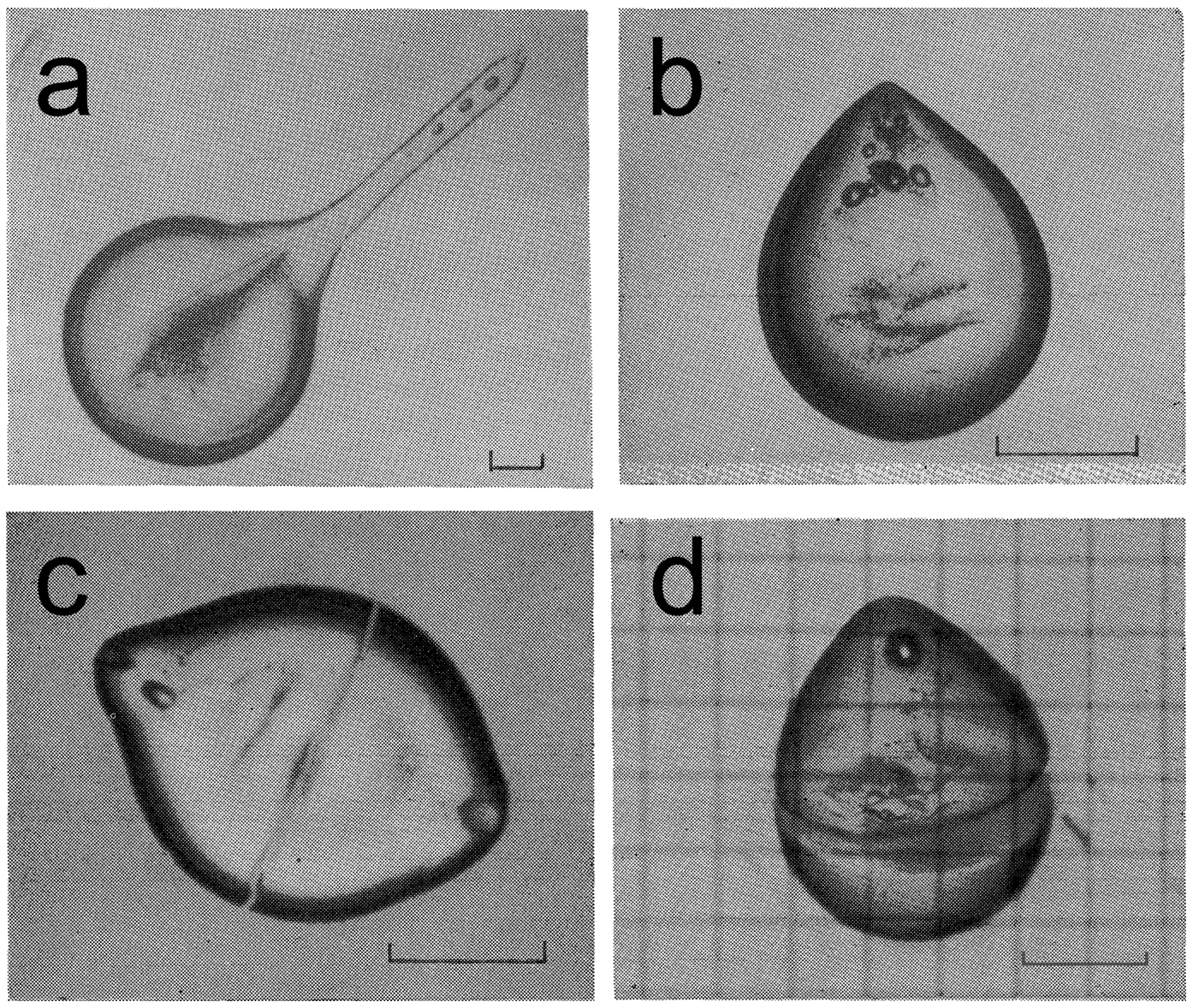

Figure 7. The main types of droplet deformations during freezing. (a) Spike: long thin protrusion usually longer than one-fourth of the drop diameter; (b) bulge: protrusion shorter than one-fourth of the droplet diameter; (c) crack; (d) split. Scales are $100 \mu \mathrm{m}$. Adapted from Takahashi (1975).

duced in the cloud chamber at positive temperatures, there is good reason to consider that they froze at temperatures higher than that of the environment. This kind of condition is favorable for spike formation (Takahashi, 1975). Deformed small droplets frozen at $T_{\mathrm{a}}<-40^{\circ} \mathrm{C}$ were also observed by Schaefer (1962).

\subsection{Fragmentation during freezing}

The following discussion will consider works focused on laboratory studies looking at the processes behind splintering and fragmentation of freezing droplets.

Mason and Maybank (1960) studied the fragmentation of freezing droplets with $30 \mu \mathrm{m}<D<1 \mathrm{~mm}$ in the temperature range of $-25^{\circ} \mathrm{C}<T_{\mathrm{a}}<2{ }^{\circ} \mathrm{C}$. Droplets were suspended on a fiber in a small $\left(\sim 40 \mathrm{~cm}^{3}\right)$ cloud chamber. It turned out that, on average, the occurrence of droplet shattering decreased with the decrease in air temperature and droplet size. The occurrence of shattering for a $1 \mathrm{~mm}$ diameter drop reached up to $47 \%$ with a maximum number of 200 splinters per drop.
Such a high rate of splinter production may be an important factor in the INP economy during precipitation formation.

However, Pruppacher (1967a) pointed out that when Mason and Maybank (1960) performed their experiments, droplets did not reach thermal equilibrium at the moment of nucleation, and their temperature $T_{\mathrm{n}}$ was higher than $T_{\mathrm{a}}$ by 1 to $12{ }^{\circ} \mathrm{C}$. The author argued that these conditions are favorable for the formation of an ice shell and for droplets freezing inward, which are critical for droplet shattering. Pruppacher questioned the relevance of the conditions used in the Mason and Maybank experiment to those in natural clouds.

Dye and Hobbs (1968) and Johnson and Hallett (1968) attempted to reproduce the Mason and Maybank (1960) experiments. They found that a $1 \mathrm{~mm}$ diameter water drop suspended on a fiber did not shatter when nucleated after attaining thermal equilibrium. Dye and Hobbs (1968) also demonstrated that enhanced concentration of dissolved $\mathrm{CO}_{2}$ resulted in increasing the occurrence of droplet shattering. They argued that the Mason and Maybank (1960) experiments were affected by increased concentrations of $\mathrm{CO}_{2}$, which was used as a coolant. Johnson and Hallett (1968, 


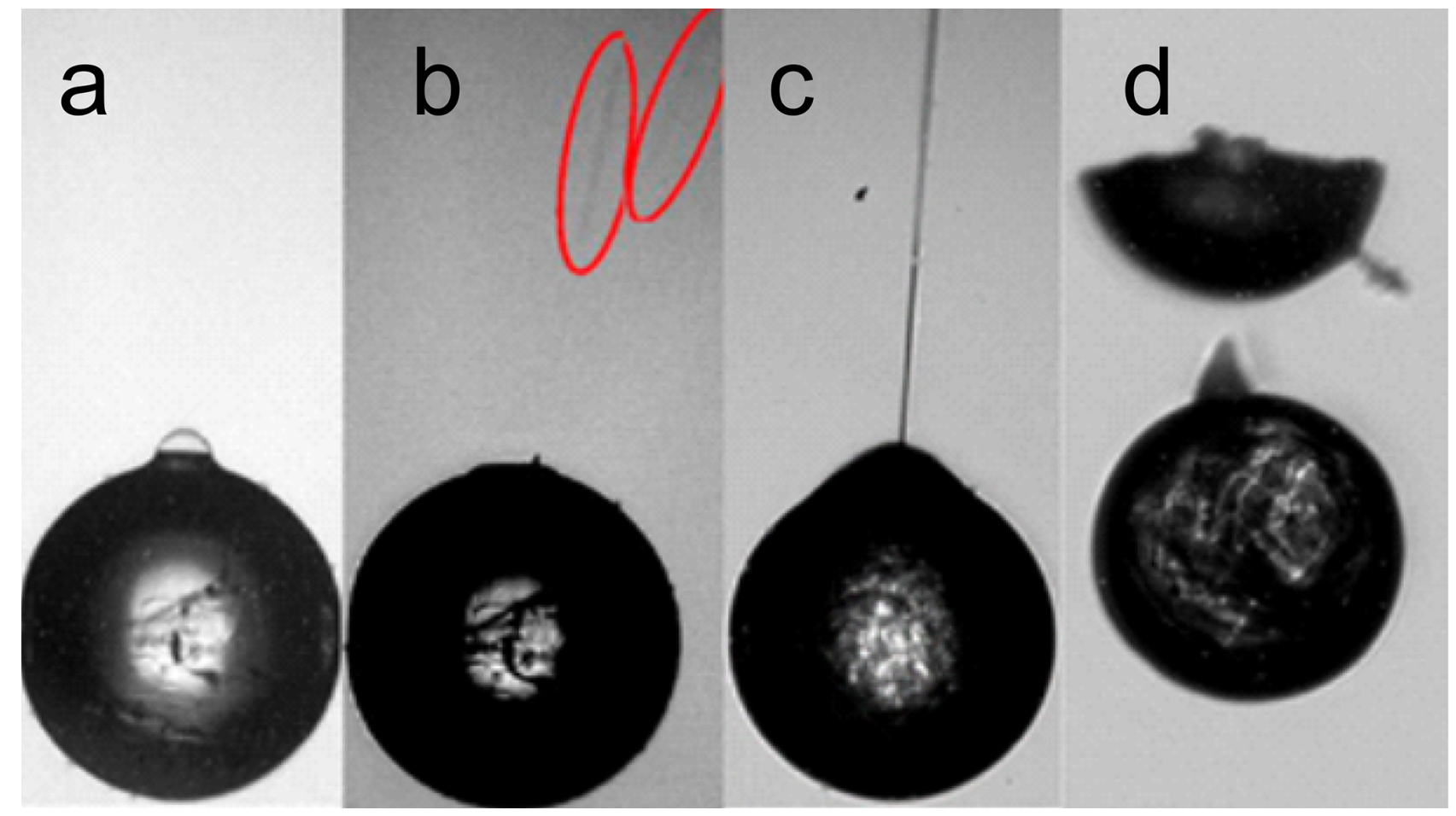

Figure 8. Secondary ice processes. (a) As observed by high-speed microscopy a bubble has formed on the surface of a freezing droplet. Cracks are visible in the surface. (b) The droplet from (a) but $12 \mathrm{~ms}$ later: the bubble has burst; two fragments are highlighted by red ellipses. (c) Jetting: a jet of liquid water is expelled violently through a hole in the ice shell. (d) Breakup: a freezing droplet splits in two halves; a few small fragments are sometimes observed (adapted from Lauber et al., 2018).

Fig. 2) also demonstrated that for the drops where the nucleating temperature was higher than that of the air $\left(T_{\mathrm{n}}>T_{\mathrm{a}}\right)$, the ice shell forms around a pure liquid core, and ice mesh does not penetrate their center. Such drops may create a stronger ice shell with a higher internal pressure and, therefore, be more susceptible to shattering.

Hobbs and Alkezweeney (1968), Takahashi and Yamashita (1969, 1970), Bader et al. (1974), Pruppacher and Schlamp (1975) found that during free fall, droplets shatter after reaching a temperature in quasi equilibrium with the environment. It is important to note that these results are in disagreement with those obtained by Dye and Hobbs (1968) and Johnson and Hallett (1968).

Despite the differences in experimental setups, most laboratory studies showed a general trend that large droplets are more susceptible to shattering during freezing than small ones (summarized in Lauber et al., 2018). However, Takahashi (1975) found that the relationship between the occurrence of shattering, droplet diameter, and air temperature is more complex. He showed that in the air temperature range $-20^{\circ} \mathrm{C}<T_{\mathrm{a}}<-7^{\circ} \mathrm{C}$, free-falling drops have the highest occurrence of shattering in the size range $75 \mu \mathrm{m}<D<$ $135 \mu \mathrm{m}$, whereas at $T_{\mathrm{a}}=-25^{\circ} \mathrm{C}$, the probability of droplet shattering nearly monotonically increases from 50 to $500 \mu \mathrm{m}$. Takahashi (1975) also found that at $T_{\mathrm{a}}=-4{ }^{\circ} \mathrm{C}$, droplets with $50 \mu \mathrm{m}<D<200 \mu \mathrm{m}$ do not shatter. In this regard, it is worth mentioning that Brownscombe and Thorndike (1968) observed a $9 \%$ occurrence of shattering in droplets with $50 \mu \mathrm{m}<D<90 \mu \mathrm{m}$ at $-5^{\circ} \mathrm{C}$. This result is in agreement with Keinert et al. (2020) reporting a $15 \%$ occurrence of droplet breakup at $-5^{\circ} \mathrm{C}$, which occurred only under freefall ventilation but not in stagnant air.

Laboratory studies also did not show a consistency for the lower threshold diameter for droplet fragmentation. Adkins (1960) found no splintering for droplets with $D<10 \mu \mathrm{m}$. Hobbs and Alkezweeney (1968) observed no fragmentation of droplets with $20 \mu \mathrm{m}<D<50 \mu \mathrm{m}$. Johnson and Hallett (1968) reported no shattering observed for droplets with $5 \mu \mathrm{m}<D<38 \mu \mathrm{m}$. However, Mason and Maybank (1960, Table 1) observed droplet shattering in the size range of $30 \mu \mathrm{m}<D<80 \mu \mathrm{m}$ when the droplets were at thermal equilibrium. The inconsistency of the latter result may be related to the enhanced concentration of $\mathrm{CO}_{2}$ in the laboratory setup. It is worth noting that based on the theoretical analysis of the energy balance, Wildeman et al. (2017) concluded that symmetrically freezing droplets smaller than $50 \mu \mathrm{m}$ in diameter cannot shatter.

Ambient air temperature has a significant effect on the occurrence of freezing-drop shattering. Both Takahashi and Yamashita (1970) and Lauber et al. (2018) found that the 
Table 1. Summary of experimental studies of droplet fragmentation during freezing by different research groups. The table covers only works that quantified the parameters included in the table.

\begin{tabular}{|c|c|c|c|c|c|c|c|}
\hline Reference & $\begin{array}{l}\text { Diameter } \\
(\mu \mathrm{m})\end{array}$ & $\begin{array}{l}\text { Temperature } \\
T_{\mathrm{a}}\left({ }^{\circ} \mathrm{C}\right)\end{array}$ & $\begin{array}{l}\text { Droplet } \\
\text { suspension }\end{array}$ & $\begin{array}{l}\text { Method of } \\
\text { nucleation }\end{array}$ & $\begin{array}{l}\text { Maximum SIP } \\
\text { frequency }(\%)\end{array}$ & $\begin{array}{r}\text { Max number } \\
\text { fragments } \\
\text { per drop }\end{array}$ & $\begin{array}{l}\text { Temperature of } \\
\text { maximum } \\
\text { SIP rate }\end{array}$ \\
\hline Mason and Maybank (1960) & $30-1000$ & -2 to $-25^{\mathrm{a}}$ & stagnant (fiber) & various $^{b}$ & 47 & 200 & $-10^{\circ} \mathrm{C}$ \\
\hline Adkins (1960) & $4-13$ & $\mathrm{NA}^{\mathrm{c}}$ & free fall & natural $^{\mathrm{d}}$ & 0 & 0 & NA \\
\hline Hobbs and Alkezweeny (1968) & $20-150$ & -8 to -32 & free fall & various $^{\mathrm{e}}$ & $>5$ & NA & $\begin{array}{l}\text { no temperature } \\
\text { dependence }\end{array}$ \\
\hline Brownscombe and Thorndike (1968) & $50-90$ & $-5,-10,-15$ & free fall & tiny ice crystals & 14 & 12 & $-15^{\circ} \mathrm{C}$ \\
\hline Dye and Hobbs (1968) & 1000 & -3 to -15 & stagnant (fiber) & tiny ice crystals & 0 & 1 & $\begin{array}{l}\text { no temperature } \\
\text { dependence }\end{array}$ \\
\hline Johnson and Hallett (1968) & 1000 & -5 to -20 & $\begin{array}{l}\text { stagnant (fiber) } \\
+ \text { ventilation }\end{array}$ & tiny ice crystals & $>1$ & NA & $\begin{array}{l}\text { no temperature } \\
\text { dependence }\end{array}$ \\
\hline Takahashi and Yamashita (1969) & $600-800$ & -18 to -25 & free fall & immersion $^{\mathrm{f}}$ & 11 & NA & $-15^{\circ} \mathrm{C}$ \\
\hline Takahashi and Yamashita (1970) & $75-350$ & 0 to -30 & free fall & tiny ice crystals & 37 & NA & $-15^{\circ} \mathrm{C}$ \\
\hline Bader et al. (1974) & $30,42,84^{\mathrm{h}}$ & -10 to -30 & free fall & immersion ${ }^{\mathrm{i}}$ & NA & 10 & NA \\
\hline Takahashi (1975) & $45-765$ & -4 to -24 & free fall & tiny ice crystals & 35 & NA & $-16^{\circ} \mathrm{C}$ \\
\hline Pruppacher and Schlamp (1975) & 410 & -7 to -23 & airflow & contact $^{g}$ & 15 & $>3$ & -11 to $-15^{\circ} \mathrm{C}$ \\
\hline Kolomeychuk et al. (1975) & 1600 & -12 to -25 & airflow $^{\mathrm{j}}$ & natural $^{\mathrm{d}}$ & 35 & 142 & -15 to $-18^{\circ} \mathrm{C}$ \\
\hline Lauber et al. (2018) & $300-320$ & -5 to -30 & stagnant (EDB) & tiny ice crystals & 35 & 12 & -7 to $-13^{\circ} \mathrm{C}$ \\
\hline Keinert et al. (2020) & $300-320$ & -1 to -30 & $\begin{array}{l}\text { stagnant } \\
\text { (EDB), airflow }\end{array}$ & tiny ice crystals & 1 & 3 & -10 to $-15^{\circ} \mathrm{C}$ \\
\hline
\end{tabular}

${ }^{\text {a }}$ Ice-nucleation temperature: $0{ }^{\circ} \mathrm{C}>T_{\mathrm{n}}>-15^{\circ} \mathrm{C} .{ }^{\mathrm{b}}$ Natural nucleation, silver iodide, contact tiny small ice crystals. ${ }^{\mathrm{c}}$ NA: not available. ${ }^{\mathrm{d}}$ No special efforts were made to nucleate droplets. ${ }^{\mathrm{e}}$ Natural or immersed silver iodide. ${ }^{\mathrm{f}}$ Kaolinite or silver iodide. ${ }^{\mathrm{g}}$ Kaolinite or montmorillonite. ${ }^{\mathrm{h}}$ Mean volume diameter. ${ }^{\mathrm{i}}$ Silver iodide.

$\mathrm{j}$ Flow of humidified nitrogen.

maximum rate of shattering is observed between -10 and $-20^{\circ} \mathrm{C}$ for droplets in size range of $85 \mu \mathrm{m}<D<350 \mu \mathrm{m}$. This is generally consistent with the results found by Brownscombe and Thorndike (1968) for droplets with $80 \mu \mathrm{m}<$ $D<120 \mu \mathrm{m}$, although their temperature range was limited by $-15^{\circ} \mathrm{C}<T_{\mathrm{a}}<-5^{\circ} \mathrm{C}$. However, for large drops with $D>500 \mu \mathrm{m}$, the maximum occurrence of shattering was observed at $T_{\mathrm{a}}<-25^{\circ} \mathrm{C}$ (Takahashi, 1975). Hobbs and Alkezweeney (1968) found that the rate of shattering of droplets with $50 \mu \mathrm{m}<D<150 \mu \mathrm{m}$ does not depend on the temperature over the range $-32{ }^{\circ} \mathrm{C}<T_{\mathrm{a}}<-20^{\circ} \mathrm{C}$, whereas in the experiments of Takahashi (1975, Fig. 7), a strong temperature dependence of droplets shattering in this size range was found.

A review of the laboratory studies showed that the reported rate of shattering during droplet freezing varied significantly. For example, Takahashi (1976) found that the maximum rate of shattering for free-fall droplets $(200 \mu \mathrm{m}<D<$ $350 \mu \mathrm{m})$ at $-20^{\circ} \mathrm{C}<T_{\mathrm{a}}<-10^{\circ} \mathrm{C}$ was close to $40 \%$. However, Lauber et al. (2018) showed that for droplets suspended in electro-dynamic balance (EDB), the maximum shattering rate for the same temperature and droplet size range is close to $12 \%$. This, however, increased notably to about $25 \%$ when the experiments were conducted under terminal velocity ventilation (Keinert et al., 2020). Brownscombe and Thorndike (1968) observed a $14 \%$ rate for shattering of freefall droplets with $80 \mu \mathrm{m}<D<120 \mu \mathrm{m}$ freezing at $-15^{\circ} \mathrm{C}$.

A significant inconsistency in the efficiencies of ice splintering and their dependency on temperature and droplet size obtained by different research groups is quite evident. This poses a key question about the differences in experimental setups and the potential effects of other parameters. Already, Johnson and Hallett (1968) have pointed out the importance of the effect of ventilation on droplet shattering. When a droplet with $D=500 \mu \mathrm{m}$ was suspended on a thread and ventilated at an equivalent-to-free-fall speed, no shattering was observed. However, when the droplet was rotated around an axis perpendicular to the airflow, shattering and cracking invariably occurred. This finding raised questions about the realism of the experiments that had a droplet suspended with a fixed orientation on a fiber or other mount. Under these conditions, the thermal exchange between the droplet and the ambient air is different compared to the free-fall condition.

Pitter and Pruppacher (1973) demonstrated that a droplet suspended in the airflow begins to tumble and spin immediately after nucleation, thus providing a radially more symmetric heat loss. Drop spinning after nucleation was also reported by Dye and Hobbs (1968), Kolomeychuk et al. (1975), and Keinert et al. (2020). Initiation of tumbling and spinning after droplet nucleation can likely be explained by the asymmetrical shape and heterogeneous surface roughness that builds up quickly after freezing, thereby leading to a fluctuating torque being exerted by the terminal airflow.

Takahashi (1976) also revealed the importance of the crystalline nature of ice that forms inside freezing drops to their subsequent shattering. He found that $90 \%-100 \%$ of shattering occurs when drops freeze as single crystals. Takahashi also showed that splitting occurs perpendicular to the $c$ axis dividing the drop in two equal parts (e.g., Fig. 7c, d). The equatorial cracking and splitting of freezing drops was also 
reported by Wildeman et al. (2017, Fig. 3a, b) and Lauber et al. (2018, Figs. 5, 6). Takahashi (1976) systematized how drops may shatter with respect to their crystalline boundaries. In most cases of polycrystalline drops, their fragmentation occurs along the crystal boundaries, where mechanical connectivity is weaker.

One of the first classifications of "types of fragmentation" during drop freezing goes back to the work of Stott and Hutchinson (1965). They nucleated 0.9 to $1.9 \mathrm{~mm}$ diameter drops that were suspended on a fiber at $-1{ }^{\circ} \mathrm{C}$ and then froze them at the air temperature of $-15^{\circ} \mathrm{C}$. Even though this particular arrangement is not fully relevant to conditions in natural clouds, it helped identify the most common patterns of the drop fragmentation. The droplet fragmentation was classified as follows: (a) violent shattering with multiple pieces, (b) central breaks or splitting, (c) spicule breaks with liquid, (d) spicule breaks after solidification, (e) spicule bubble breaks, and (f) cracks.

Wildeman et al. (2017) conducted experiments with millimeter-sized drops freezing on a superhydrophobic substrate. The high-speed videos documented explosive shattering of freezing drops, which generated a cascade of ice fragment sizes. One of the videos (V2) documented secondary shattering of one of the fragments formed after primary shattering. This suggests that during droplet freezing, liquid water may form several pockets across the droplet volume, rather than one big unfrozen volume in the central part. As discussed above, the connectivity of unfrozen pockets of water inside the ice shell is likely to be controlled by the type of the ice network formed inside the droplet and temperature exchange between the droplet and environment.

One of the caveats of the Wildemann et al. (2017) laboratory setup is that the experiments were performed at very low pressure $\left(3.4 \times 10^{-3} \mathrm{~atm}\right)$, and the droplets cooled much faster than they would cool in the atmosphere. Johnson and Hallett (1968) showed that below 0.13 atm, every drop in their experiments shattered violently. In this way, the results are not directly applicable to environmental conditions.

In a series of experiments conducted with electrically charged droplets levitated in an electrodynamic balance, Alexei Kiselev and colleagues observed droplet freezing with a high-speed video microscope and categorized secondary ice processes as breakup, cracking, bubble bursting, and jetting; cf. Fig. 8. Opposite to previous studies, they did not observe violent shattering of freezing droplets into many fragments. The relative and absolute frequency of the secondary processes did not only depend on droplet size and temperature, but also on droplet ventilation and the presence of solid inclusions or dissolved salts. The effect of solid inclusions (polystyrene latex particles) was 2 -fold. While they suppressed droplet shattering upon freezing of large $(D=300 \mu \mathrm{m})$ drizzle droplets (Lauber et al., 2018), they strongly enhanced droplet shattering in small $(D=80 \mu \mathrm{m})$ drizzle droplets (Pander et al., 2015). Large droplets were found to shatter at higher temperatures and much more fre- quently when suspended at terminal air velocity compared to being suspended in stagnant air under otherwise identical conditions (Keinert et al., 2020).

Dissolved sea salt hindered droplet shattering at all sizes at concentrations above about $100 \mathrm{mg} \mathrm{L}^{-1}$. It is reasoned that dissolved substances and solid inclusions are expelled from the growing ice phase and concentrate in the liquid phase during freezing. Here, they hinder the formation of a monocrystalline ice shell. So, on one hand, this reduces the pressure needed for breakup, but on the other hand, it may open pathways for pressure release prior to breakup.

Pressure-release events such as jetting or spiking have been found to occur. Once high concentrations of dissolved gases build up in the liquid phase of the droplet interior, pressure release induces gas bubble formation in the droplet interior. These bubbles may escape through spikes or cracks in the ice shell giving rise to bubbles. Upon freezing of the bubble skin, the skin breaks and may form a source of additional tiny ice particles. Even though bubble bursting has been found to be a frequent secondary ice process (Pander et al., 2015; Lauber et al., 2018), the number of emitted ice particles has not been quantified up to date. Droplet ventilation had a major influence on secondary ice process frequency and type (Keinert et al., 2020).

Droplets moving at terminal velocity with respect to the surrounding air generally showed more frequent secondary ice processes when compared to droplets levitated in stagnant air. The dominant process observed shifted from cracking at stagnant conditions to breakup under free-fall conditions. The latter could be observed even at temperatures higher than $-5^{\circ} \mathrm{C}$.

King and Fletcher (1973) hypothesized that the numerous discontinuities in the pressure changes inside the freezing drops are indicative of the large-scale movements of the ice shell, and therefore, it may be a source of particles, even if the droplet does not shatter. This hypothesis was confirmed in experimental studies of droplet freezing by Wildeman et al. (2017). The production of ice splinters during cracking of $2 \mathrm{~mm}$ freezing drop was documented in the supplementary high-speed video V2. Visual analysis of this video allowed for the identification of several ice splintering events during cracking prior to final droplet shattering. Four of those events are shown in Fig. 9. In general, the number of secondary ice particles due to droplet cracking during freezing could be formulated as the product of the number of cracking events per freezing event and the average number of secondary particles per cracking event. However, the actual number of splinters during cracking events may be higher in comparison to those observed visually. This is because microphotography allows for the detection of only those splinters that occurred within the depth of field of the microscope or whose sizes were larger than the detecting threshold of the optical system and because not all cracking events are detectable by optical microscopy. 

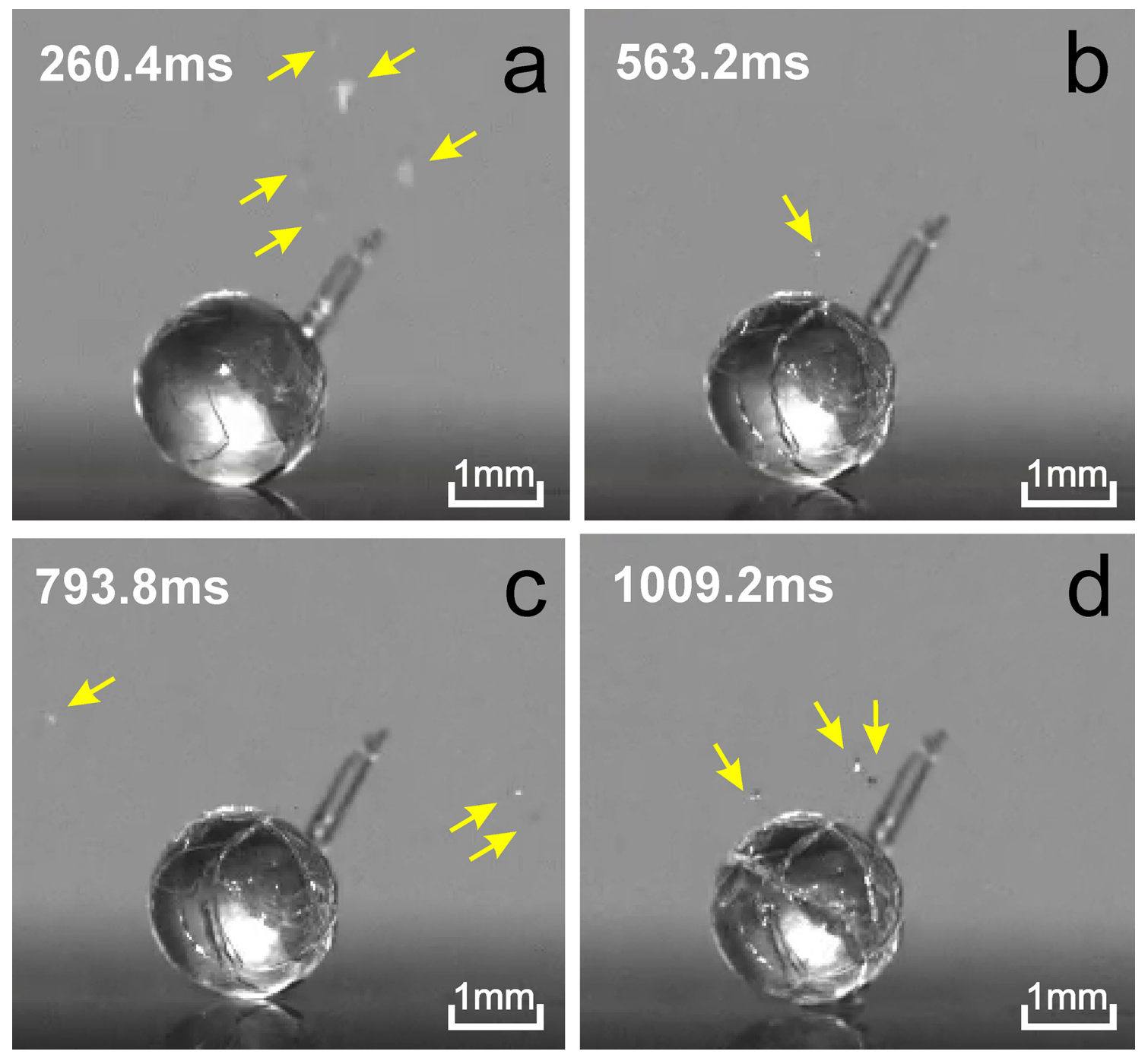

Figure 9. High-speed video snapshots of a $2 \mathrm{~mm}$ drop at different stages of freezing. The pictures show progressive increase in the number of cracks covering the drop during its freezing. The yellow arrows indicate the locations of ice splinters ejected during cracking. The ambient temperature $T=-7^{\circ} \mathrm{C}$. The numbers in the top left corners indicate time since nucleation. Adapted from video V2 from the supplementary material to Wildeman et al. (2017).

Splintering during cracking is an important finding, since it shows that freezing droplets may be a source of secondary ice, even though they do not shatter by the end of freezing.

\subsection{Summary}

The review of the laboratory studies showed that the fragmentation of freezing drops is sensitive to a number parameters such as (a) droplet size $D$, (b) environmental temperature $T_{\mathrm{a}}$, (c) droplet nucleating temperature $T_{\mathrm{n}}$, (d) air pressure $P$, (e) type of ice mesh formed during the recalescence stage (dependant on $T_{\mathrm{n}}$ ), (f) crystalline nature of freezing droplet (i.e., monocrystalline or polycrystalline), (g) thermal conductivity of surrounding medium $K$, (h) size of nucleating particle (small INP vs. large ice particle, affects polycrystallinity), (i) ventilation $f\left(D, T_{\mathrm{a}}, P\right)$ (e.g., static air, drop rotation during freezing and free fall), (j) fall velocity $u_{z}\left(D, T_{\mathrm{a}}, P\right)$, and (k) dissolved gases (specifically $\mathrm{CO}_{2}$, dependent on $T_{\mathrm{a}}$ and $P$ ). Several types of ice fragmentation during droplet freezing were documented: (1) splitting with few fragments, (2) explosive shattering with multiple fragments, (3) cracking-splintering, (4) bubble bursting, and (5) jetting. Unfortunately, the dependency of ice fragmentation during droplet freezing on the above parameters remains only partially understood.

A review of the laboratory studies on droplet freezing showed a large diversity of obtained results. The summary of the laboratory studies on droplet fragmentation during freezing is shown in Table 1. Thus, for a single experimental setup under the same conditions, the number of frag- 

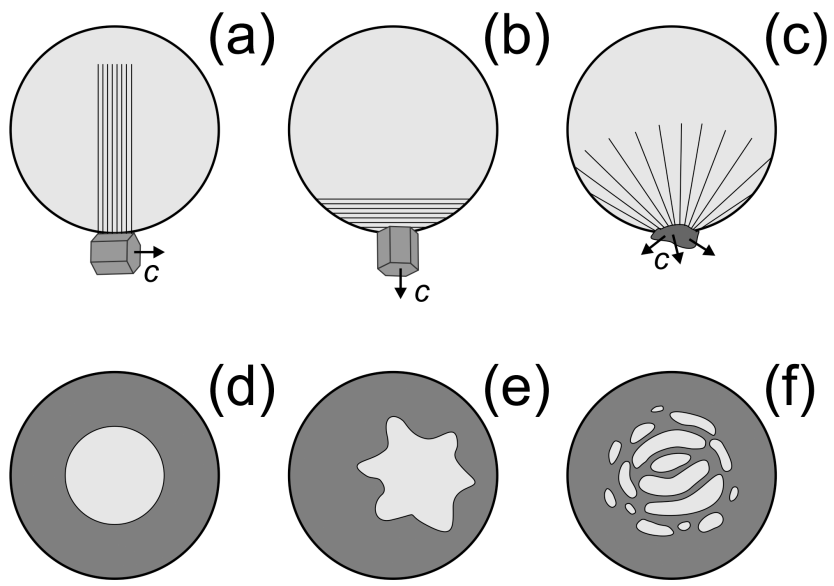

Figure 10. A conceptual diagram showing different possibilities of freezing of a supercooled droplet after nucleation by (a) monocrystalline INP or ice crystal with $c$ axis parallel to the droplet surface, (b) monocrystalline INP or ice crystal with $c$ axis perpendicular to the droplet surface, and (c) polycrystalline INP or ice crystal. The visuals in (d-f) show various possible topologies of liquid zones formed during freezing: (d) idealized spherical liquid volume symmetrically centered with the ice shell (frequently used in numerical simulations of droplet freezing), (e) non-symmetrical liquid volume displaced towards the ice shell wall, and (f) multiple disconnected liquid volumes.

ments formed for the same size drop during its freezing varied from zero to a few hundred. Similarly, under the same laboratory conditions, studies observed that only a fraction of the droplets shattered, whereas the other fraction did not produce any fragments. This suggests that the laboratory experiments might contain hidden non-controlled parameters, which hindered obtaining reproducible results for each freezing droplet.

One of these parameters may be the orientation of the crystallographic axis of the INP with respect to the droplet surface at the moment of nucleation (Fig. 10a-c). Since the growth rate of ice along the $a$ and $c$ axes is different (e.g., Macklin and Payne, 1968), the process of the droplet filling with the ice network during the recalescence stage may create different types of nonuniform temperature distributions inside the droplet and ultimately affect the symmetry of the ice shell. In the case of a polycrystal INP, it is expected that during the recalescence stage, a droplet will be filled by the ice network more uniformly (Fig. 10c) as compared to a monocrystalline INP (Fig. 10a, b).

Humidity of the surrounding environment may be another hidden aspect affecting SIP (Keinert et al., 2020). Depending on the humidity level, the droplet may either grow or evaporate prior to nucleation. This may create additional temperature gradients at the droplet surface, depending on its diameter. The near-surface temperature gradients may either hinder or facilitate the formation of the ice shell.
The topology of liquid volumes inside the freezing drop may also be an important factor for SIP. Thus, the cracking rate may be affected by the symmetry of the ice shell as well as the displacement of the liquid core with respect to the droplet center (Fig. 10d, e). The tensile stress formed in the ice shell is also expected to depend on how liquid water volumes are distributed across the freezing droplets: inside one big (Fig. 10d, e) or multiple small volumes (Fig. 10f). Unfortunately, no attention was given to this effect in previous laboratory studies.

There are a number of other parameters which received little attention in laboratory experiments that include (a) size distribution of ice fragments; (b) minimum size of splinters, which may form during fragmentation; (c) minimal size for droplets to shatter; (d) effect of the angle between the $c$ axis and the droplet surface on ice shell formation; and (e) humidity of the air.

Growing evidence from in situ observations (e.g., Korolev et al., 2004, 2020; Rangno, 2008; Lawson et al., 2017) suggests that fragmentation during droplet freezing is an important SIP contributor to the concentration of cloud ice particles. Unfortunately, the diversity of laboratory results related to fragmentation during drop freezing hinders the development of a quantitative description and refined theory of this mechanism for use in cloud simulations. A variety of parameters and fragmentation types make the experimental studies and quantification of this mechanism a challenging and intricate problem.

\section{Splintering during riming}

\subsection{Efficiency of rime splintering}

Splintering during ice particle riming is another mechanism that can explain SIP. Macklin (1960) observed splinter production in a small wind tunnel during the collection of droplets on an icing rod with $0.6 \mathrm{~cm}$ diameter at temperatures of $-5^{\circ} \mathrm{C}<T_{\mathrm{a}}<-20^{\circ} \mathrm{C}$. The droplet diameters in their size distribution varied from a few to $140 \mu \mathrm{m}$ (mean volume diameter: $\sim 67 \mu \mathrm{m}$ ), and their speed changed from 2 to $12 \mathrm{~m} \mathrm{~s}^{-1}$. A microscopic examination revealed long spicules, and a few micrometer-sized ice features formed on the surface of the rod. The small fragile formations were hypothesized to be a source of the splinters. The ice crystal concentration during experiments was frequently observed to increase by a few orders of magnitude, reaching values on the order of $10^{-1} \mathrm{~cm}^{-3}$ at temperatures as high as $-5^{\circ} \mathrm{C}$.

Latham and Mason (1961) observed riming of freezing droplets on the hailstone simulator, accompanied by the ejection of ice splinters. They established that the splinter production varied with the air temperature, drop diameter, and impact velocity. A maximum production rate of 14 splinters per droplet, was observed in droplets with a diameter of $70 \mu \mathrm{m}$, impacting at $10 \mathrm{~m} \mathrm{~s}^{-1}$ at a temperature of $-15^{\circ} \mathrm{C}$. 


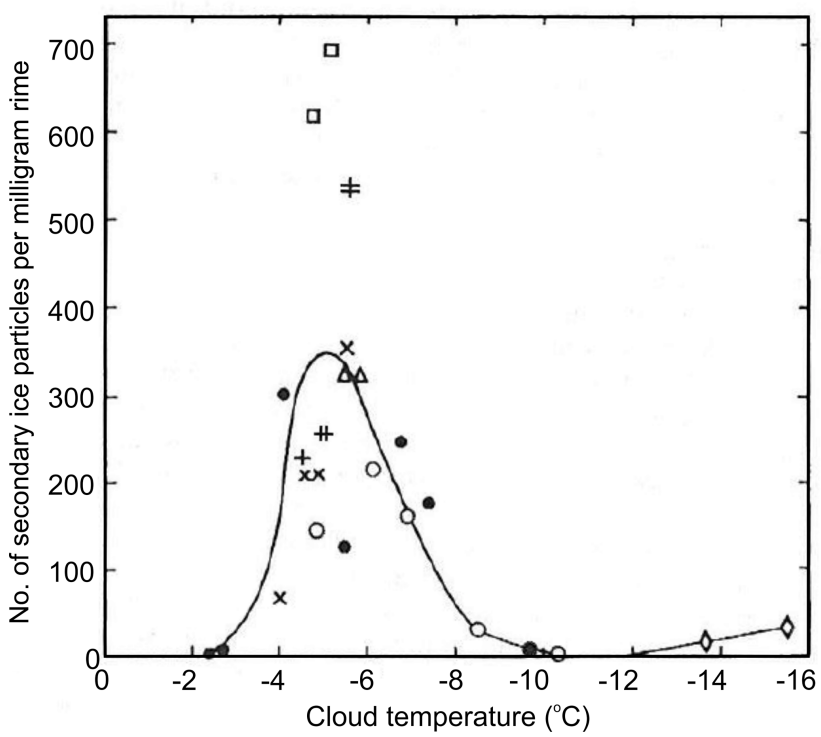

Figure 11. The dependence of the number of splinters per milligram of rime on ambient temperature at speed $2.7 \mathrm{~m} \mathrm{~s}^{-1}$ obtained experimentally by Hallett and Mossop (1974).

Hobbs and Burrows (1966) and Aufrermaur and Johnson (1972) studied charge separation between an ice target and the flow of cloud particles on impact with each other. However, no significant ice splintering was found in either experiment. Hobbs and Burrows (1966) argued that the high rate of splintering observed by Latham and Mason (1961) may be related to carbon dioxide, which might be present in the experimental setup.

Bader et al. (1974) observed rime splintering during accretion of monodisperse droplets on a small copper target. The experiments were conducted for an ambient temperature in the ranging of $-15^{\circ} \mathrm{C}<T<-9^{\circ} \mathrm{C}$. Droplets fell at terminal velocity and were deposited on the rimer. The number of accreted droplets per ejected ice splinter decreased from 2000 for droplets of $56 \mu \mathrm{m}$ diameter to 200 for droplets of $100 \mu \mathrm{m}$ diameter. These numbers correspond to 5 and 10 ice particles per milligram of rime, respectively. Ice particles were only ejected when there was an open, chain-like structure on the rimer surface. However, no ice fragments were seen when water accretion was high enough to give a completely glazed deposit. The latter was likely associated with reaching the Ludlam limit (Ludlam, 1951).

Hallett and Mossop (1974) and Mossop and Hallett (1974) observed splinter formation during riming in a cloud chamber with liquid water content of $\sim 1 \mathrm{~g} \mathrm{~m}^{-3}$ and droplet concentration of $500 \mathrm{~cm}^{-3}$. They found that splinter production is active in the temperature range $-8^{\circ} \mathrm{C}<T_{\mathrm{a}}<-3^{\circ} \mathrm{C}$. Furthermore, the rate of splinter production had a pronounced maximum at the air temperature of $-5^{\circ} \mathrm{C}$ and the drop impact velocity of $2.5 \mathrm{~m} \mathrm{~s}^{-1}$ (Fig. 11). With these conditions, one splinter was produced per 250 droplets of diameter $D>$
$24 \mu \mathrm{m}$. The phenomenon of splinter production during riming is usually referred to as the Hallett-Mossop (HM) mechanism.

Mossop (1978, 1985b) found that the presence of droplets with $D<12 \mu \mathrm{m}$ in addition to those with $D>24 \mu \mathrm{m}$ increases the splinter production further. Saunders and Hosseini (2001) studied the splinter production in a wider range of impact velocities of up to $12 \mathrm{~m} \mathrm{~s}^{-1}$. They found that the maximum secondary ice ejection occurs at $6 \mathrm{~m} \mathrm{~s}^{-1}$ with the number of splinters nearly 5 times lower than it was found in the Hallett and Mossop (1974) and Mossop and Hallett (1974) experiments.

The amount of dissolved gases is typically not specified in most laboratory experiments. Even if equilibrium has been reached, in nature this amount might depend on the chemical composition of the droplet, e.g., cloud droplet $\mathrm{pH}$ value.

Heymsfield and Mossop (1984) studied the effect of the rimer surface temperature on the production of secondary ice particles. They found that raising the surface temperature of the riming particle by $1^{\circ} \mathrm{C}$ transposes the splinter production curve virtually unchanged to air temperatures $1^{\circ} \mathrm{C}$ lower. This led the authors to conclude that splinter production due to the HM mechanism may occur at air temperatures lower than $-8^{\circ} \mathrm{C}$, depending on liquid water content (LWC) and the rimer fall velocity, which are the main factors determining the surface temperature of the riming particle. This conclusion is consistent with earlier work by Foster and Hallett (1982).

The quantification of the rime-splintering production obtained from the experimental studies of Hallett and Mossop (1974) created a basis for various formulations of SIP parameterizations (e.g., Cotton et al., 1986; Meyers et al., 1997; Reisner et al., 1998; and others), which are widely used in numerical simulations of clouds.

\subsection{Physical mechanism of rime splintering}

Several studies are aimed at understanding the physical mechanisms responsible for splinter production. For instance, Macklin (1960) documented that fine ice structures formed during riming could be easily detached from the rimer and form splinters. One of these fine ice features is shown in Fig. 12a.

Mossop (1976) proposed four possible mechanisms responsible for the HM process: (1) formation of ice shell around accreted droplets with its subsequent fragmentation during freezing, (2) detachment of droplets that make glancing contact with rime, (3) growth and subsequent detachment of frail ice needles at temperatures around $-5^{\circ} \mathrm{C}$, and (4) detachment of rimed ice by evaporation (see Sect. 6).

Choularton et al. $(1978,1980)$ suggested that if droplets with $D>25 \mu \mathrm{m}$ are accreted to the ice substrate by a thin neck, they will minimize the heat transfer toward the rimer. This arrangement may induce symmetrical heat loss to the air, which then leads to the formation of a complete ice shell 

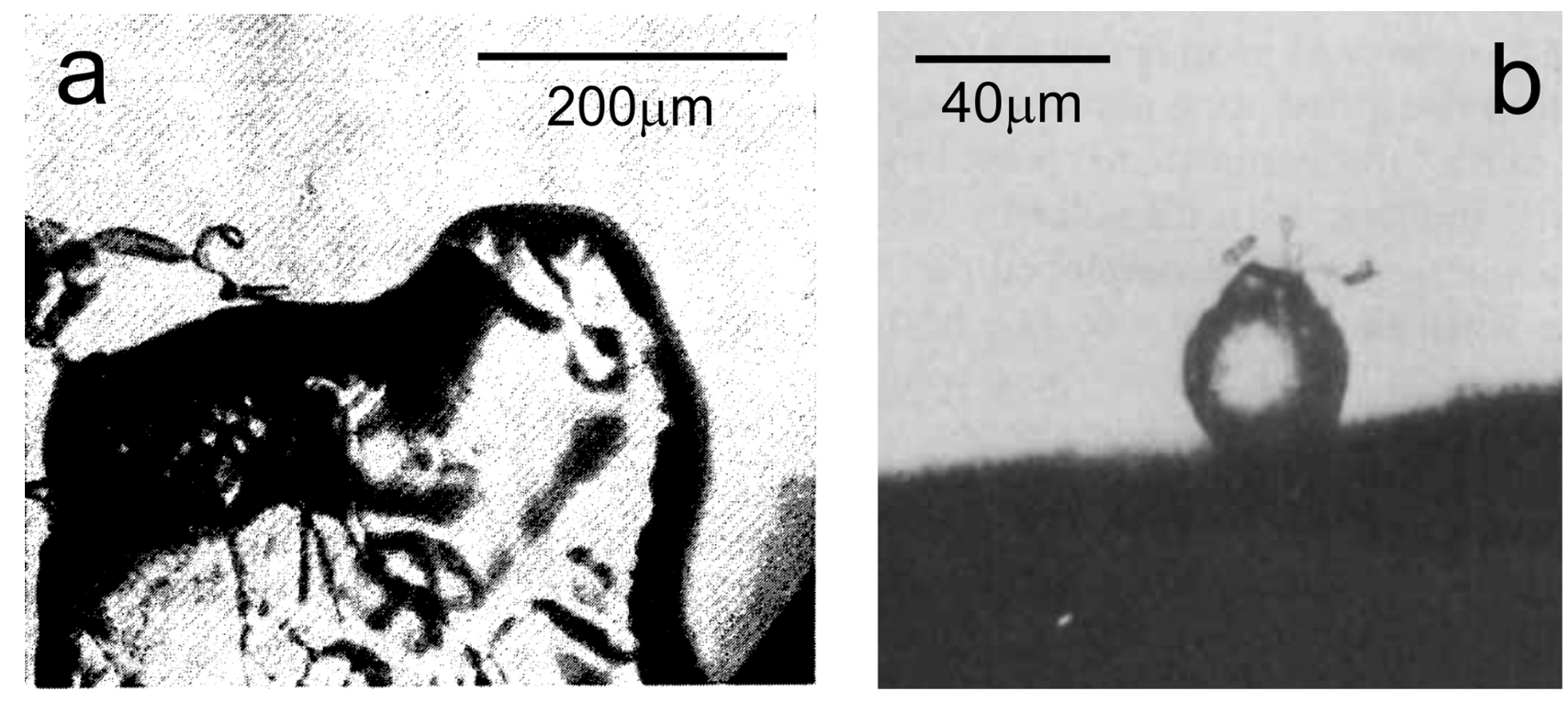

Figure 12. Pictures of the rime fragments: (a) frozen splash observed at $T_{\mathrm{a}}=-6^{\circ} \mathrm{C}$ and a speed of $6 \mathrm{~m} \mathrm{~s}^{-1}$ (Macklin, 1960); (b) disruptions of protuberances formed out of a $35 \mu \mathrm{m}$ rimed droplet at $T_{\mathrm{a}}=-7^{\circ} \mathrm{C}$ and speed $1.5 \mathrm{~m} \mathrm{~s}^{-1}$ (Choularton et al., 1980).

around a droplet as it freezes. The freezing of liquid will result in a pressure buildup inside the droplet which may cause shell disruptions with subsequent production of fragile protuberances of frozen water (Fig. 12b). Mossop (1980) credited this hypothesis by pointing out that the ice shell is weakened by the presence of ammonia and results in a reduced number of protuberances and splinters. He also showed that the increased ammonia concentration in droplets results in a reduction of the rate of splinter production. Griggs and Choularton (1983) suggested that the cutoff at about $-8^{\circ} \mathrm{C}$ is due to rapid growth of the ice shell, which is too strong to be disrupted by the internal pressure.

Dong and Hallett (1989) reported that after impact with ice, droplets tend to spread over the surface of ice at all temperatures above $-8^{\circ} \mathrm{C}$. They concluded that splinter production by pressure buildup inside individual frozen droplets is unlikely to be responsible for the shattering. They suggested that fragmentation is associated with the stress buildup within an accreted droplet. This occurs when the droplet experiences a temperature gradient between the colder substrate and the surface of the droplet, freezing at $0^{\circ} \mathrm{C}$. However, the absence of protuberances, when the droplets rime onto an ice surface above $-10^{\circ} \mathrm{C}$, contrasts with the observation of Choularton et al. (1980), which showed photographs of discrete frozen droplets together with protuberances obtained in the temperature range -3 to $-7^{\circ} \mathrm{C}$ (Fig. 12b).

Emersic and Connoly (2017) studied microscopic riming events on an ice target using a high-speed video recording. The droplet sizes ranged from 5 to $50 \mu \mathrm{m}$. It was found that the droplet behavior on impact depends on the uniformity of the rimer surface. Thus, droplets tend to spread flat on flat ice surfaces at temperatures associated with the HM pro- cess, as was earlier observed by Macklin and Payne (1969) and Dong and Hallett (1989). However, with increasing rime depth, which is more commonly associated with graupel, growing rime spires protrude from the surface into the airflow around the rimer. No protuberances or liquid ejection was observed during the riming process, nor was any mechanical rime-splintering event observed in approximately 1300 droplet freezing events. Based on the results of their study, Emersic and Connoly (2017) hypothesized that the rime spikes that develop with continuing droplet accretion could break off during particle tumbling or hinging by small droplets.

\subsection{Summary}

The literature review showed that, apart from some early studies (Hobbs and Burrows, 1966; Aufrermaur and Johnson, 1972), most laboratory experiments on the HM process confirmed splinter production during riming. However, there was no consistency in the rate of the rime splintering observed by different groups. This can be clearly seen from Table 2 summarizing main laboratory results of the HM-process studies. This discrepancy is most likely related to different laboratory setups and techniques used for splinter counting.

The analysis of laboratory studies suggests that the efficiency of secondary ice production during the HM process depends on (a) air temperature $T_{\mathrm{a}}$ (max efficiency at $-8^{\circ} \mathrm{C}<T_{\mathrm{a}}<-3^{\circ} \mathrm{C}$ ); (b) surface temperature of the rimer $T_{\mathrm{S}}$ (depends on $u_{z}$ and LWC); (c) size $L_{\mathrm{r}}$ and density $\rho_{\mathrm{r}}$ of the rimer; (d) fall speed of the rimer $u_{z}$, determined by the size and density of the rimer and air density $u_{z}\left(L_{\mathrm{r}}, \rho_{\mathrm{r}}, \rho_{\mathrm{a}}\right)$; (e) droplet size distribution $F(D)$. The condition applied 
Table 2. Summary of experimental studies of rime splintering (HM process). The table covers only works that quantified the parameters included in the table.

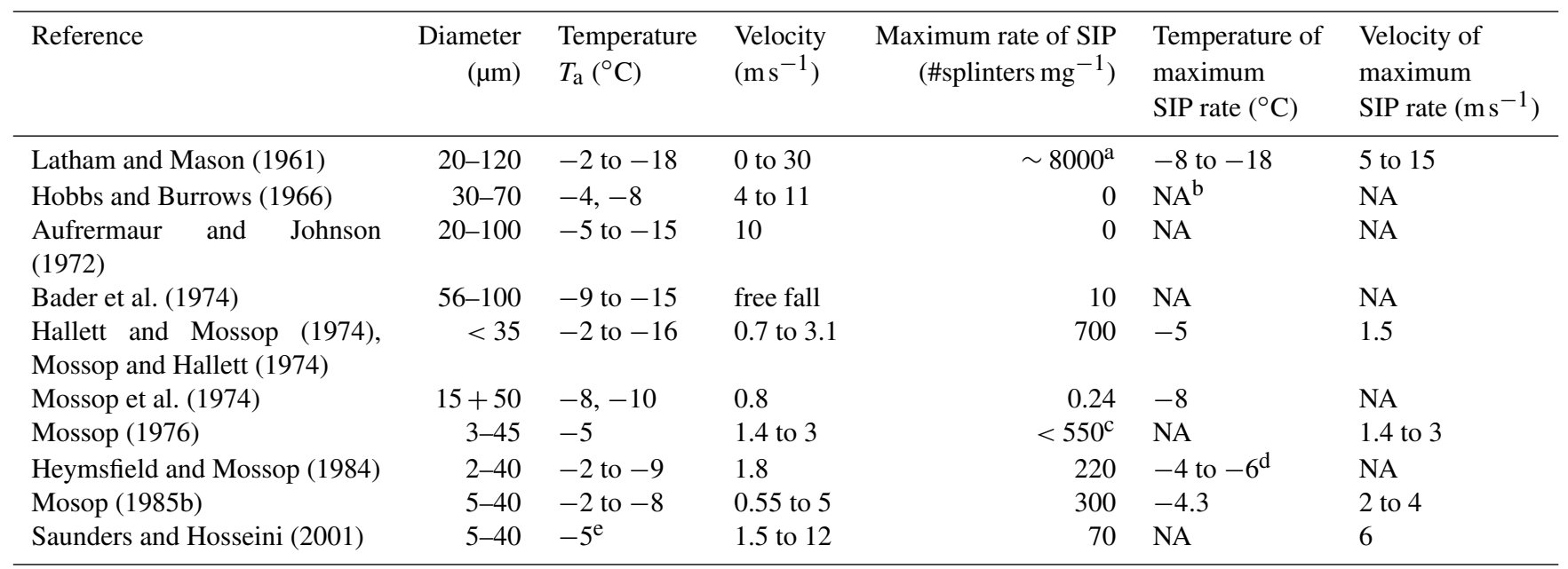

${ }^{\mathrm{a}}$ Fourteen splinters per droplet $70 \mu \mathrm{m}$ diameter. ${ }^{\mathrm{b}}$ NA: not available. ${ }^{\mathrm{c}}$ One splinter per 250 droplets $>24 \mu \mathrm{m}$ diameter. ${ }^{\mathrm{d}}$ Depending on LWC. ${ }^{\mathrm{e}}$ Rimer surface temperature $T_{\mathrm{s}}$.

to $F(D)$ requires presence of droplets with $D>24 \mu \mathrm{m}$ and $D<12 \mu \mathrm{m}$. Another condition for $F(D)$ limits maximum LWC by the Ludlam limit (Ludlam, 1951) when the rimer growth will turn into wet growth. In this case, the rimer's surface will be covered by a layer of liquid water, which will suppress splintering.

To conclude this section, it should be emphasized that after several decades of rime-splintering studies, the physical mechanisms behind this phenomenon are still under debate. Without clarifying the nature of this process, a development of a physically based parameterizations for numerical simulations of clouds does not seem to be feasible.

\section{Fragmentation due to ice-ice collision}

Collision of ice particles may result in their mechanical fragmentation and production of secondary ice (Langmuir, 1948, p. 186). This hypothesis was stimulated by observations of ice particle fragments collected during airborne (e.g., Hobbs and Farber, 1972; Takahashi, 1993) or ground-based (Jiusto and Weickmann, 1973) studies.

There were only two known laboratory works on collisional ice fragmentation. Vardiman (1978) explored fragmentation of natural cloud ice particles on impact with a metal mesh. He found that "graupel is surprisingly ineffective in generating fragments". However, light-to-moderaterimed spatial crystals are the most efficient source of ice fragments. For planar crystals, the degree of fragmentation increases with the degree of riming.

Takahashi et al. (1995) studied the dependence of mechanical fragmentation resulting from collision of $2 \mathrm{~cm}$ in diameter rimed ice spheres. The ice spheres were attached to the edges of $10 \mathrm{~cm}$ long spinning metal rods and were made to collide with each other at a speed of $4 \mathrm{~m} \mathrm{~s}^{-1}$. This speed was used to simulate a fall speed of a $4 \mathrm{~mm}$ diameter lump graupel with a density of $0.3-0.4 \mathrm{~g} \mathrm{~m}^{-3}$. The collisional force incrementally changed from $2 \times 10^{-4}$ to $5 \times 10^{-3} \mathrm{~N}$. Takahashi et al. (1995) found that the number of fragments depends on the degree of riming, temperature, and collision force. The maximum number of fragments per collision (up to 800) was observed at $-16^{\circ} \mathrm{C}$.

It is hard to judge the consistency of the results obtained by Vardiman (1978) and Takahashi et al. (1995) because of the differences in the experimental setups and environmental conditions. It is also difficult to identify the degree of applicability of the rate of SIP obtained in these experiments to free-falling ice particles grown in natural clouds.

Collisional ice fragmentation was also studied theoretically by Hobbs and Farber (1972), Vardiman (1978), and Phillips et al. (2018). These studies were based on the consideration of collisional kinetic energy and linear momentum. Such considerations would be relevant only for cases of direct central impact. In a general case, angular momentum and rotational energy should be taken into consideration. Since oblique particle collisions are more frequent than central collision, the efficiency of SIP obtained in these works is expected to be overestimated.

The theoretical considerations of collisional fragmentation in Yano and Phillips (2011), Yano et al. (2016), and Phillips et al. (2018) were based on the rate of ice production from Takahashi et al. (1995). A detailed analysis of the Takahashi et al. (1995) laboratory setup indicated that the riming of ice spheres occurred in still air, which resulted in more lumpy and fragile rime compared to that formed in free-falling graupel. The collisional kinetic energy and the surface area of collision of the $2 \mathrm{~cm}$ diameter ice spheres also significantly exceed the kinetic energy and collision area of graupel whose 
typical size is a few millimeters. Altogether, it may result in overestimation of the rate of SIP, compared to graupel formed in natural clouds.

It should also be mentioned that ice particle fragments observed in situ (e.g., Hobbs and Farber, 1972) may be a result of particle breakups induced by the sampling instrument (see Sect. 8). Schwarzenboeck et al. (2009) identified that $18 \%$ of observed incomplete dendrites are the result of natural fragmentation. The identification of natural fragments was based on the observation of the ice shapes near the expected break area, which were interpreted as "subsequent growth". However, it could be argued that incomplete dendrites may naturally form because of growth suppression of one or more branches due to defects or dislocations on the crystal. Examples of 1-, 2-, 3- and 4-branched stellar and dendritic crystals with underdeveloped defected branches were documented by Bentley and Humphreys (1962, pl. 198-204), Auer (1970, Figs. 9, 28, 30), Kikuchi and Uyeda (1979, Fig. 2).

The analysis of literature suggests that the efficiency of SIP during ice-ice collision depends on (a) properties of the colliding particles, such as size, mass, density, shape, surface roughness; (b) air temperature $T_{\mathrm{a}}$ (determines physical properties of ice, e.g., crispness); and (c) relative fall velocity of colliding particles (depends on the aerodynamic size of particles and air density).

In summary of this section, it can be concluded that the efficiency of SIP during ice-ice collisional fragmentation remains uncertain due to the lack of laboratory studies. No parameterizations of SIP due to ice-ice collisional fragmentation can be developed at that stage based on two laboratory observations, whose results are conflicting with each other. Additional laboratory studies are required to explore ice-ice collisional fragmentation of free-falling ice particles with different habits. Ice fragments observed in situ should be considered with caution due to potential particle breakups during sampling (see Sect. 8).

\section{Fragmentation due to thermal shock}

When a supercooled drop rimes on the surface of an ice crystal, it freezes, and its temperature rises to the melting point (Sect. 2.2). Some fraction of the latent heat released during freezing will be transferred into the ice crystal. Koenig (1963, p. 35) hypothesized that this may cause a thermal shock at the location of the droplet attachments with following ice crystal cracking and splintering due differential expansion of ice.

From the lab experiments of Gold (1963), it was found that the surface temperature shock of $6^{\circ} \mathrm{C}$ is necessary to produce the stress required for ice cracking.

Dye and Hobbs (1968) observed during laboratory experiments that when an ice crystal on some occasions became attached to a freezing drop, it would often break into 5 to 10 pieces as the drop froze. Sometimes, the breakup of the crystal would occur when the drop cracked. On other occasions the crystal would break without any apparent changes to the freezing drop. Later Hobbs and Farber (1972) reproduced laboratory experiments of Dye and Hobbs (1968). They observed shattering of a dendritic crystal into several pieces after bringing it in contact with a $2 \mathrm{~mm}$ diameter supercooled drop. These observations are of considerable interest, for it suggests that the breaking up of ice crystals that collide and nucleate supercooled drops may play an important role in increasing the concentration of ice particles in natural clouds.

Using thermoelastic theory, King and Fletcher (1976a) calculated thermal stresses in idealized ice shapes on impact with liquid droplets when a small area was warmed to $0^{\circ} \mathrm{C}$. They concluded that a thermal shock mechanism is unlikely to be responsible for SIP at temperatures of $T_{\mathrm{a}}>-5^{\circ} \mathrm{C}$.

King and Fletcher (1976b) conducted a series of experiments to study the effect of thermal shock on cracking of macroscopic polycrystalline spheres $(D \approx 2-3 \mathrm{~cm})$ and thick $(\Delta h=1.7 \mathrm{~cm})$ and thin $(\Delta h=1-2 \mathrm{~mm})$ cylindrical plates with diameter $b=5 \mathrm{~cm}$ at temperatures down to $-40^{\circ} \mathrm{C}$. The cracking probability of ice plates versus temperature was studied for several ratios $a / b=0.2,0.4$, and 0.6 , where $a$ is the diameter of the heated area. In such an arrangement, the thermal shock is expected to be more severe than that experienced by microscopic ice crystals during riming. Depending on the thickness of the plates and the ratio $a / b$, the cracking temperature threshold varied from -5 to $-35^{\circ} \mathrm{C}$. None of the plates fragmented or separated. King and Fletcher (1976b) concluded that thermal shock is unlikely to be an important ice multiplication mechanism at $-5^{\circ} \mathrm{C}$.

Experiments using thermal shock with macroscopic slabs and spheres by King and Fletcher (1976b) are not fully scalable down to microscopic monocrystalline ice particles. Moreover, the conclusions obtained in their studies are not consistent with the laboratory observations of Gold (1963), Dye and Hobbs (1968), and Hobbs and Farber (1972).

The review of the studies of SIP due to fragmentation of ice particles due to thermal shock depends on (1) air temperature $T_{\mathrm{a}}$, (b) mass and shape of the ice particle, (c) droplet diameter, (d) local geometrical configuration of the ice particle at the location of the droplet attachment, (e) relative velocity of the droplet and ice particle at the moment of impact (determines thermal connection of the droplet and ice particle), and (f) ventilation (determines convective heat losses to the air).

Despite the seeming feasibility of this SIP process to occur in natural clouds, this phenomenon got little attention from the cloud physics experimental community. Based on the previous experimental and theoretical studies, the efficiency of ice fragmentation due to thermal shock is expected to primarily depend on the air temperature, droplet size, ice crystal size, and its habit. Unfortunately, none of these dependencies have been addressed experimentally. Therefore, the effect of thermal shock ice fragmentation on SIP remains inconclusive. 


\section{Fragmentation of sublimating ice particles}

Ice particle fragmentation and formation of secondary ice may occur during sublimation in subsaturated cloud regions. Mossop et al. (1974, Sect. 4c) observed sublimation of rimed particles under the microscope. They reported detachment of $20 \mu \mathrm{m}$ size rime from their original locations and identified it as an "unexpected phenomenon", which may explain SIP.

Oraltay and Hallet (1989) studied evaporation of ice particles suspended on a fiber at a wind speed emulating their fall velocity. They observed the fragmentation of dendritic ice shapes at subfreezing temperatures only when relative humidity over ice was $\mathrm{RH}_{\mathrm{i}}<70 \%$ and ventilation velocity was 10 to $20 \mathrm{cms}^{-1}$. However, no sublimation breakup was observed for columnar and plate-like crystals. Dong et al. (1994) studied fragmentation of rimed ice and needles at $50 \%<\mathrm{RH}_{\mathrm{i}}<90 \%$, with $-18^{\circ} \mathrm{C}<T_{\mathrm{a}}<-5^{\circ} \mathrm{C}$ and a ventilation speed of $\sim 1 \mathrm{~m} \mathrm{~s}^{-1}$. In their experiments, they found that rimed ice particles that are a few millimeters long may generate up to 100 fragments during evaporation at $\mathrm{RH}_{\mathrm{i}}<$ $70 \%$ within $1-2 \mathrm{~min}$.

Bacon et al. (1998) studied fragmentation of sublimating ice particles suspended in electrodynamic balance inside a thermo-diffusional chamber at $85 \%<\mathrm{RH}_{\mathrm{i}}<100 \%$ and $-30{ }^{\circ} \mathrm{C}<T_{\mathrm{a}}<0{ }^{\circ} \mathrm{C}$. The observed fragmentation tended to affect prolate ice particles with an aspect ratio higher than 3 . An example of images of sublimating ice particle is shown in Fig. 13. All three studies concluded that breakup rates depend on temperature and humidity but largely on the initial shape of the ice particle.

During in situ observation of metamorphosis of shapes of sublimating ice particles in natural clouds, Korolev and Isaac (2004) came to a conclusion that ice particle fragmentation during sublimation does not play an important role in SIP.

The laboratory experiments suggest that fragmentation of ice particles depends on the (a) ice particle shape and size, (b) relative humidity, (c) pressure, (d) air temperature $T_{\mathrm{a}}$, and (e) fall velocity and ventilation coefficient.

In order for the ice fragments formed during sublimation to result in ice multiplication, they have to re-enter back into a supersaturated cloud region. Since small ice fragments have lower terminal fall velocity, their residence time in the undersaturated environment may be long enough to result in their complete evaporation before they can re-enter a supersaturated environment. This appears to be a significant limitation of the SIP mechanism due to sublimation breakup. This mechanism is also unlikely to explain explosive concentrations of small ice crystals frequently observed in convective and stratiform frontal clouds (e.g., Lawson et al., 2017; Korolev et al., 2020).

\section{Activation of INPs in transient supersaturation around freezing drops}

Muchnik and Rudko (1961) and Dye and Hobbs (1968) reported observation of a halo of small droplets formed around a freezing drop immediately after the moment of its nucleation. Dye and Hobbs (1968) explained the origin of small droplets by the activation of CCNs in the region of high transient $^{1}$ supersaturation formed around freezing droplets. After ice nucleation, the droplet surface temperature $T_{\mathrm{s}}$ rises to $0^{\circ} \mathrm{C}$. Under the condition that the surrounding air has $T_{\mathrm{a}}<0{ }^{\circ} \mathrm{C}$, the surface of the freezing drop acts as a source of water vapor to a colder environment. The resulting water vapor diffuses radially outward. Depending on the air humidity, it may create at some distance from the droplet a region with supersaturated air. Nix and Fukuta (1974) developed a theoretical framework for the calculation of the supersaturation field around a stationary freezing drop, which was determined by molecular diffusion. They showed that maximum supersaturation increases with the decrease in $T_{\mathrm{a}}$ and the increase in drop size.

Cheng (1970) attempted to explain the origin of small droplets due to their ejection from the freezing drop. However, this explanation was challenged by Hobbs (1971). Rosinski et al. (1972) also described laboratory results refuting Cheng's interpretation of the halo around freezing drops.

Later, Gagin (1972) proposed a mechanism explaining SIP due to activation of INP in high transient supersaturation area around freezing drops. He argued that high supersaturation may result in activation of insoluble INPs, which normally do not activate at typical cloud supersaturation levels ( $\mathrm{SS}<$ $1 \%)$

Rosinski et al. (1975) studied activation of silver iodide and soil particles placed on a flat plate at different distances from $2 \mathrm{~mm}$ freezing drops. They found that silver iodide nucleated as water at temperatures of $T_{\mathrm{a}}>-9.8^{\circ} \mathrm{C}$ and as ice at $T_{\mathrm{a}}<-9.8^{\circ} \mathrm{C}$. Soil particles with sizes 20 and $40 \mu \mathrm{m}$ nucleated as water at temperatures of -20 and $-16^{\circ} \mathrm{C}$, respectively, and as ice at lower temperatures. Rosinski et al. (1975) concluded that "production of ice particles by condensationfollowed-by-freezing in a parcel of a cloud containing large freezing drops is orders of magnitude higher than by contact nucleation".

Gagin and Nozyce (1984) suspended 1-2 mm diameter drops inside a gradually cooling chamber. The drops froze at a mean temperature $-6.5^{\circ} \mathrm{C}$ as they contained silver iodide. Complete drop freezing occurred in 5-6 min, when the ambient temperature decreased down to $-10-12{ }^{\circ} \mathrm{C}$. From the aerosol in the ambient air, they found that during drop freezing on average 1.6-2.1 ice crystals were activated around freezing drops. The nucleation of ice crystals was attributed to supersaturation-sensitive INPs.

\footnotetext{
${ }^{1}$ Some studies use the term "transitional".
} 


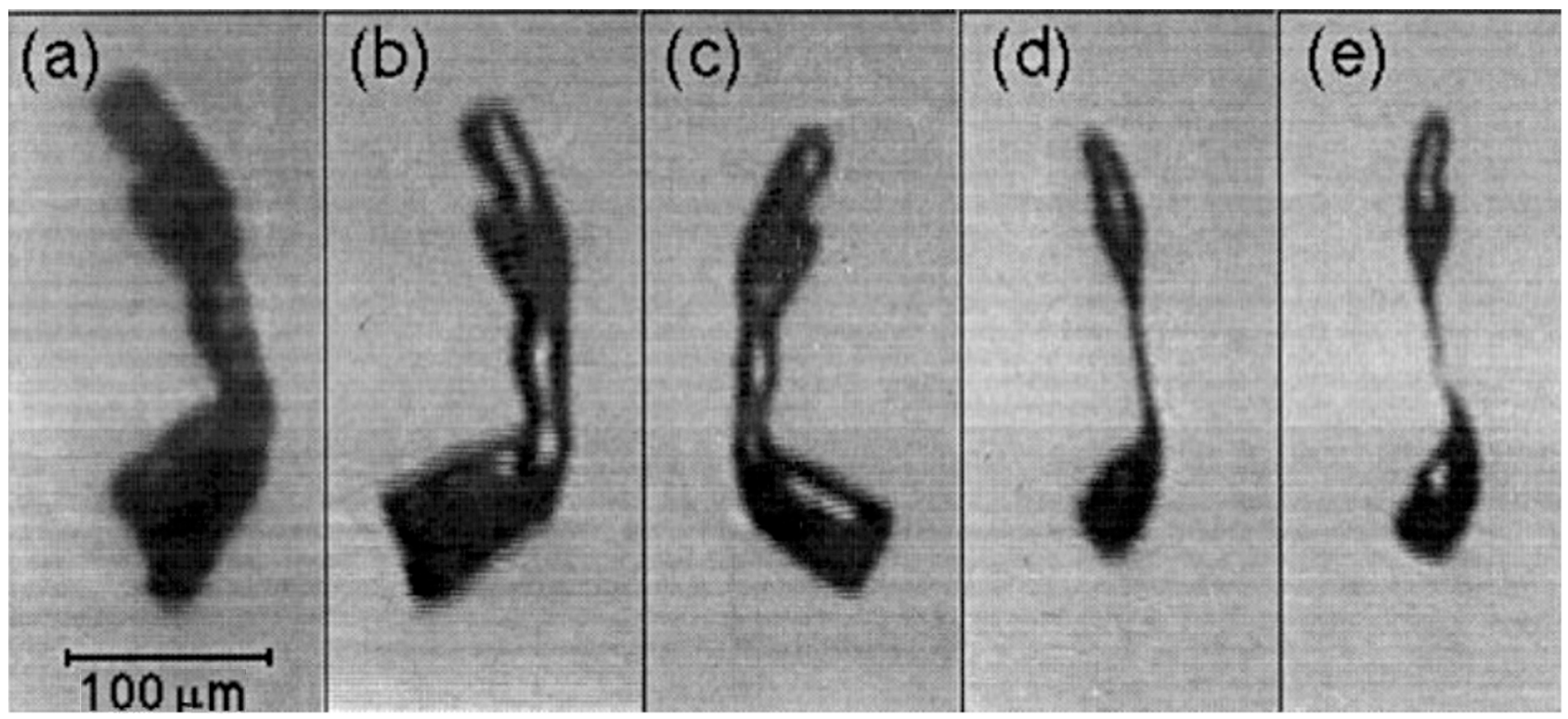

Figure 13. A sequence of images of a sublimating ice particle levitated in an EDB. Time before breakup (a) $6 \mathrm{~min}$, (b) $4 \mathrm{~min}$, (c) $2 \mathrm{~min}$, (d) $20 \mathrm{~s}$, and (e) at the moment of breakup (Bacon et al., 1998).

In laboratory experiments of Rosinski et al. (1975) and Gagin and Nozyce (1984) the transient supersaturation in addition to the molecular diffusion was also contributed by a mixing with a convective flow, induced by the temperature difference between the drop surface and environment. None of the above studies accounted for a ventilation effect for free-falling drops. In this regard, it was not clear whether the obtained results are applicable to natural clouds, since the mixing will occur in the wake of falling drops, and it will be mainly determined by turbulent mixing.

Iwabuchi and Magono (1975), in experiments on freezing electrification, documented formation of fog along the trajectories of 90-160 $\mu \mathrm{m}$ free-falling freezing drops at $T_{\mathrm{a}}=$ $-65^{\circ} \mathrm{C}$ (Fig. 14a, b). They used the fog formation to identify the start and end moments of the drop freezing.

Prabhakaran et al. (2020) conducted experiments with a $2 \mathrm{~mm}$ diameter free-falling drops in an environment with $T_{\mathrm{a}}=-18{ }^{\circ} \mathrm{C}$ and $\mathrm{RH}_{\mathrm{w}}=60 \%-80 \%$. The experiments were conducted using Snomax and AgI aerosols introduced into the ambient air. The drop temperatures varied in the range $0{ }^{\circ} \mathrm{C}<T_{\mathrm{S}}<+20^{\circ} \mathrm{C}$. The high drop temperatures were used to enhance supersaturation and exaggerate ice nucleation in the undersaturated air. The free-falling drops formed fog trails consisting of activated cloud droplets and ice (Fig. 14c, d).

Nix and Fukuta (1974) also pointed out that hailstones during wet growth have a surface temperature close to $0{ }^{\circ} \mathrm{C}$, and therefore they may act as a source of high supersaturation. Under such conditions, hailstones may activate many more supersaturation-sensitive INPs than a freezing droplet, since the affected volume in such a case will be much larger.
Fukuta and Lee (1986) performed calculations of supersaturation around falling graupel with different sizes $(2,4$, and $6 \mathrm{~mm})$ at different ambient temperatures $(-10,-20$, and $-30^{\circ} \mathrm{C}$ ). They found that larger graupel with larger sweeping volume has lower maximum supersaturation. Thus, over 2 and $6 \mathrm{~mm}$, the falling graupel maximum supersaturation with respect to water at $-10,-20$, and $-30^{\circ} \mathrm{C}$ reaches approximately $10 \%, 40 \%$, and $100 \%$ and $5.5 \%, 23 \%$, and $35 \%$, respectively. The finding that for falling freezing drops, the maximum supersaturation is decreasing with the increase in the drop size is opposite to that for stationary drops in Nix and Fukuta (1974).

Chouippe et al. (2019) performed direct numerical simulations (DNSs) of a free-falling ice sphere in humid air accounting for heat and mass transfer. This study was focused on exploring accuracy of numerical simulation. It confirmed the conclusion obtained in previous studies that supersaturation increases with the increase in the temperature difference $\Delta T=T_{\mathrm{S}}-T_{\mathrm{a}}$. Krayer et al. (2020) used the same DNS model. They found that significant values of supersaturation can be attained in the wake of warm hydrometeors, which persist long enough to be observed at more than 50 particle diameters downstream of the meteor for sufficiently high differences in temperature. The supersaturated volume of air exceeds the estimations by Fukuta and Lee (1986) by far, which is attributed to the more accurate representation of the flow in the DNS model.

It is worth noting that high transient supersaturation may form in cases other than over a particle with a surface temperature of $T_{\mathrm{s}}>T_{\mathrm{a}}$. A similar effect may also occur over a graupel or hailstone, for which the surface temperature did 

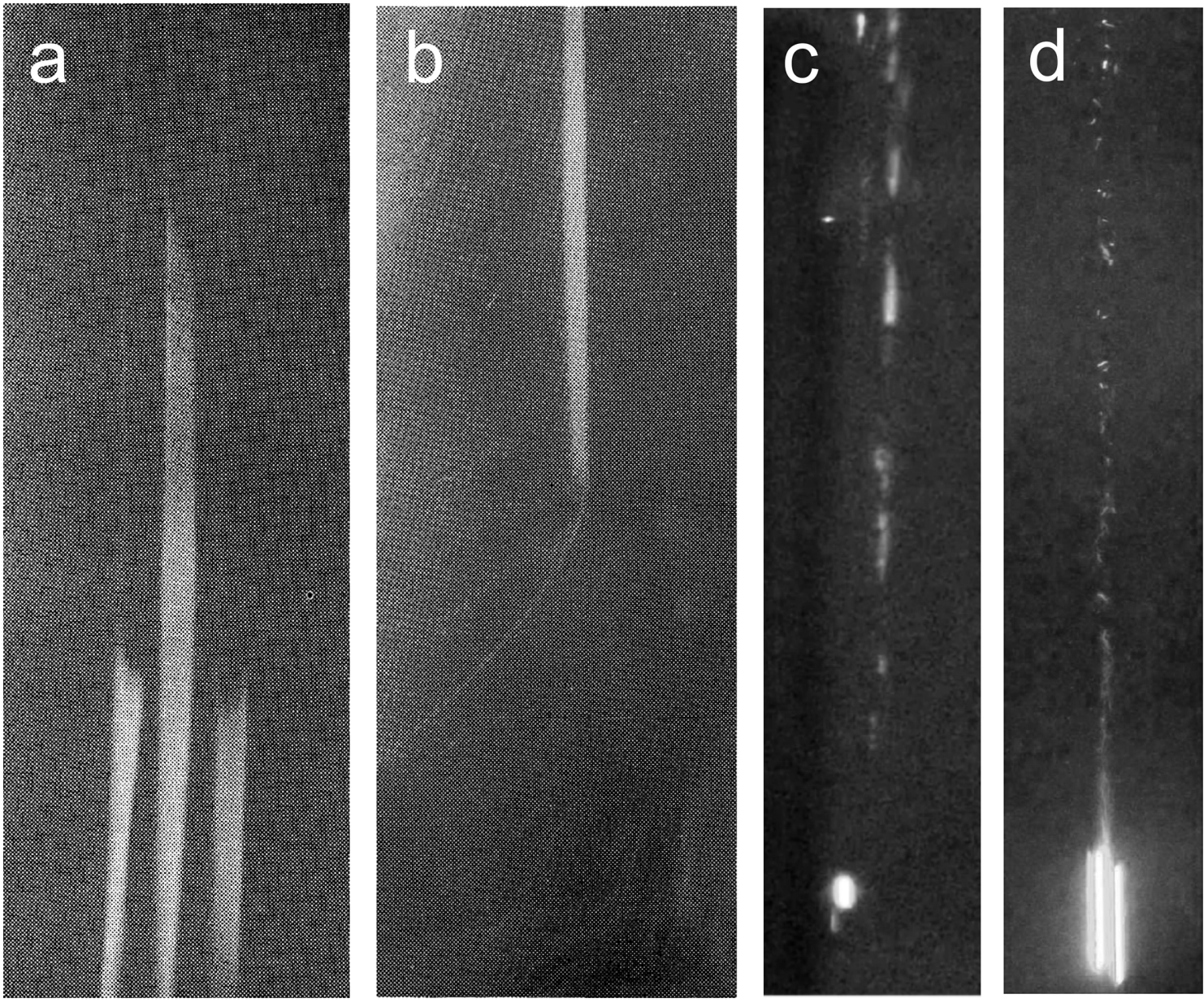

Figure 14. The trajectories of falling drops with $D=100 \mu \mathrm{m}$ visualized by nucleation of CCN and INP in the high supersaturation formed around freezing drops at the moment of (a) initiation of freezing and (b) by the end of freezing at ambient temperature $T_{\mathrm{a}} \approx-65^{\circ} \mathrm{C}(\mathrm{Iwabuchi}$ and Magono, 1975). Nucleation of water droplets and ice particles in the wake of falling with $D \approx 2 \mathrm{~mm},(\mathbf{c}) T_{\mathrm{a}} \approx-20^{\circ} \mathrm{C}, \mathrm{RH}_{\mathrm{w}} \approx 60 \%$, and $0{ }^{\circ} \mathrm{C}<T_{\mathrm{a}}<2{ }^{\circ} \mathrm{C}$; (d) $T_{\mathrm{a}}=18^{\circ} \mathrm{C}, \mathrm{RH}_{\mathrm{W}}=60 \%$, and $T_{\mathrm{S}}=10^{\circ} \mathrm{C}$. In these experiments $\mathrm{AgI}$ and of Snomax were used as ice nuclei (Prabhakaran et al., 2020).

not reach equilibrium and remains lower than the ambient air. Thus, Schaefer and Cheng (1971, Fig. 1a) observed initiation of ice around a simulated graupel with temperature $5^{\circ} \mathrm{C}$ lower than the ambient air temperature. Unfortunately, no other details of the experimental setup were available from their work.

The above studies suggest that the activation of INP is expected to grow with the increase in the temperature difference $T_{\mathrm{s}}-T_{\mathrm{a}}$. However, Baker (1991) argued that even if $T_{\mathrm{a}}$ is as low as $-15^{\circ} \mathrm{C}$, the total volume with high supersaturation around all freezing drops remains too small to enhance the number concentration of active INPs by several orders of magnitude. Therefore, INP activation in transient supersaturation around freezing drops should have a low significance for SIP. This result seems to be conflicting with the conclusion obtained in Rosinski et al. (1975) and Prabhakaran et al. (2020). It should be noted that the Baker (1991) assessment of the SIP efficiency was obtained for the static field of supersaturation around droplet and under the assumption that the number concentration of active INPs follows a power law in supersaturation that could be extrapolated to a very high supersaturation.

In summary of this section it can be concluded that efficiency of SIP due to INP activation in transient supersaturation depends on (a) droplet diameter $D$, (b) air temperature $T_{\mathrm{a}}$, (c) droplet surface temperature $T_{\mathrm{s}}$, (d) droplet fall speed $u_{z}$, (e) relative humidity RH, (f) air density $\rho_{\mathrm{a}},(\mathrm{g})$ turbulence intensity $\varepsilon$, (h) droplet freezing time (depends on $D, T_{\mathrm{a}}, \rho_{\mathrm{a}}$, $u_{z}, \mathrm{RH}$, and $\varepsilon$ ), and (i) concentration and nucleation activity of interstitial INPs.

The studies described above provide experimental and theoretical support that activation of supersaturation-sensitive INPs in the wake of free-falling freezing drops, wet hailstones, or riming graupel is one of possible mechanisms of SIP. Unfortunately, due to limited experimental studies, the effect of INP activation around falling hydrometeors cannot 
be quantified and employed in cloud simulations. Future laboratory studies should be focused on the behavior of INPs at very high ice supersaturation ( $>10 \%$ ) for a better the quantification of the effect of $T_{\mathrm{S}}-T_{\mathrm{a}}$ of a free-falling hydrometeor on the INP activation.

\section{Spurious enhancement of ice concentration during sampling}

In this section we discuss results of experimental studies of artificial fragmentation of ice particles during in situ sampling. Artificial ice particle fragmentation may result in a significant enhancement of the measured ice concentration and be confused with SIP. Airborne in situ measurements are the main source of information about the concentration of ice particles in natural clouds and the environmental conditions associated with SIP. The accuracy of in situ measurements of small ice particles is of great importance for the closure of SIP parameterizations and provides feedback to laboratory studies.

At the initial stage of regular cloud observations with optical particle probes (Knollenberg, 1981), it was found that small ice particles were observed in all ice clouds including precipitating and undersaturated cloud regions where existence of small particles conflicted with their small fall velocity and rapid sublimation, respectively. Such observations required developing additional mechanisms to explain the omnipresence of small ice crystals.

The hypothesis of enhanced ice concentration induced by airborne instruments has been discussed over a long period of time. Larger ice particles may bounce off the forward probe's tips or inlet and shatter into smaller fragments. After rebounding, the shattered fragments may travel into the probe's sample volume and cause multiple artificial counts of small ice. Cooper (1977) was the first to recognize a potential significance of instrumental particle shattering and suggested filtering the shattered artifacts based on the characteristically short interarrival times between successive particles passing through the probe's sample volume. Several following works based on comparisons between several airborne instruments (Gardiner and Hallett, 1985; Gayet et al., 1996) or analysis of the particles' interarrival time (Field et al., 2003) posed the question of whether the observed high concentration of ice particles is real or an artifact.

Korolev and Isaac (2005) documented optical array probe OAP-2DC and OAP-2DP as well as high-volume precipitation spectrometer (HVPS) images of fragmented precipitation-sized ice particles as a direct evidence of the existence of shattering. However, it did not clarify the origin of the enhanced concentration of small ice.

Field et al. (2006) applied an interarrival time algorithm to identify and filter out shattering artifacts in OAP-2DC and the cloud-imaging probe (CIP) measurements. It was found that after filtering artifacts, the OAP-2DC and CIP concen-

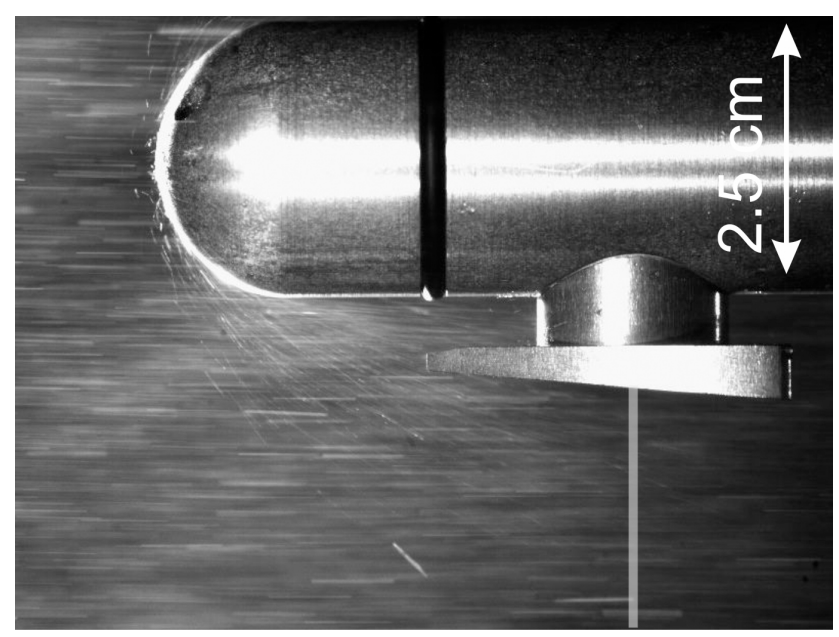

Figure 15. A snapshot from a high-speed video showing a flow of shattered ice fragments rebounding from the hemispherical tip of the OAP-2DC particle probe. The shattered ice fragments deflected toward the sample area (bright vertical band) are counted by the probe and artificially enhance the measured concentration. The video recording was performed in an ice spray at $80 \mathrm{~m} \mathrm{~s}^{-1}$ in the Cox and Co. Icing Wind Tunnel Facility (for more details see Korolev et al., 2011, 2013a, b).

trations were reduced by up to a factor of 4 , when the massweighted mean size exceeded $3 \mathrm{~mm}$.

Heymsfield (2007), McFarquhar et al. (2007), Jensen et al. (2009), and Vidaurre and Hallett (2009), based on the comparisons between different airborne instruments, built up more evidence about the spurious enhancement of concentration of small ice particles.

Despite the growing evidence of the significance of the effect of shattering on ice particle measurements, the shattering hypothesis was not commonly accepted in the cloud physics community for many years. Many researchers argued that shattered particle fragments, after bouncing from the probe's upstream surface, shed along the surface of the arms or inlets and that they could not travel several centimeters across the airflow at an aircraft speed of $100 \mathrm{~m} \mathrm{~s}^{-1}$ to reach the probe's sample volume.

A direct experimental support for the shattering hypothesis has been provided by a series of wind tunnel experiments with controlled environment and reproducible ice spray conditions (Korolev et al., 2011, 2013b). Ice particle impacting with the probe tips at aircraft speed were video-recorded by a high-speed camera. These videos documented that after rebounding from the probe's tips, shattered small fragments can travel several centimeters across the airflow and reach the probe's sample volume (Fig. 15).

Korolev et al. (2011, 2013a), Lawson (2011), Korolev and Field (2015), and Jackson et al. (2015) showed that the effect of shattering can be mitigated by using both antishattering Korolev tips (K-tips) (Korolev et al., 2013b) and the interarrival time algorithm (Field et al., 2006). It was also demon- 
strated that the interarrival time algorithm, when used alone, is not capable of identifying all shattering artifacts. Korolev et al. (2013a) showed that measured concentration of ice particles smaller $200 \mu \mathrm{m}$ can be enhanced due to the shattering effect by up to 2 orders of magnitude, whereas the concentration of ice particles larger than $400 \mu \mathrm{m}$ remains mainly unaffected.

Another source of artifacts in measurements of high concentration of ice particles by optical array probes (OAPs), is related to fragmentation of particle images when particles pass through the sample volume close to the edge of the depth of field (DoF) (Korolev, 2007; Vaillant de Guélis et al., 2019). A few 1- to 2-pixel images that resulted from fragmentation of large out-of-focus images have an enhanced artificial contribution to the particle concentration due to their very small sample volumes. This is a purely optical phenomenon, and it is relevant only to imaging particle probes. Currently, the problem of fragmented images is recognized by many research groups. One of possible solutions of this problem is the exclusion of the first two or three size bins compromised by the ambiguity of the DoF definition and contamination by image fragments. Due to the extent that particle counts from the first two or three size bins (smaller than 30-80 $\mu \mathrm{m}$, depending on the OAP type) may significantly contribute to the ice concentration, a limitation is imposed on the measurements of total concentration of ice particles in SIP cloud regions.

These findings brought up a question of whether early airborne studies of SIP were contaminated by shattering artifacts, which resulted in an artificial enhancement of the measured concentration of small ice. However, numerous recent in situ measurements, which employed the antishattering techniques and updated processing algorithms, are in general consistent with the early SIP observations, and they also showed that in many clouds, ice particle concentrations are still much higher than the INP concentration (e.g., Crosier et al., 2011, 2014; Crawford et al., 2012; Heymsfield and Willis, 2014; Stith et al., 2014; Lawson et al., 2015, 2017; Lloyd et al., 2015; Lasher-Trapp et al., 2016; Keppas et al., 2017; Ladino et al., 2017; Korolev et al., 2020; and others).

\section{Concluding remarks}

\subsection{General comments}

Figure 16 shows a summary diagram with conceptual models of six SIP mechanisms discussed above.

The analysis provided in this work shows that the experimental studies SIP are distributed quite unevenly between different mechanisms. Most of the SIP experimental works are associated with examining the mechanism of droplet fragmentation during freezing (33 publications). ${ }^{2} \mathrm{~A}$

\footnotetext{
${ }^{2} \mathrm{~A}$ publication is considered related to a specific SIP mechanism, if it includes experimental results related to this specific
}

large number of laboratory works are dedicated to studying rime splintering (HM process) (22 publications). The other four mechanisms received far too little attention from the lab research community: ice-ice collisional fragmentation (2 publications), thermal shock fragmentation (3 publications), sublimating ice fragmentation (9 publications), and INP nucleation in transient supersaturation ( 5 publications). Even though none of the above mechanisms have a complete quantitative theoretical description, there is a reasonably good understanding of what physical processes are involved in these mechanisms with the exception of the HM process. The situation regarding the HM process is contradictory; on one hand, the parameterization of the HM mechanism is widely used in cloud simulations and weather prediction models, while on the other hand, there is no clear understanding of the physical processes underlying this mechanism. At the same time, none of the other five mechanisms are employed on a systematic basis in weather prediction models.

The most striking outcome of this review is the diverse range of results obtained by different research groups for each of the SIP mechanisms. This is one of the major issues hindering the development of physically based parameterizations for numerical simulations. On the other hand, the diversity of the results of laboratory studies challenges the existing SIP parameterizations employed in numerical simulations of clouds and weather prediction models.

\subsection{Feasibility of SIP mechanisms}

One of the important questions related to ice multiplication is whether all six mechanisms can occur in natural clouds.

The review of the lab experiments suggests that the mechanism of droplet fragmentation during freezing may be active across a wide range of temperatures. There is an increasing amount of evidence indicating universality of this mechanism, which may occur in both convective and stratiform clouds.

The rime-splintering (HM) mechanisms require the presence of heavily rimed graupel with high fall velocity. Formation of such graupel is most likely to occur in convective mixed-phase cloud regions in a quite narrow temperature range of $-8{ }^{\circ} \mathrm{C}<T_{\mathrm{a}}<-3{ }^{\circ} \mathrm{C}$.

Ice-ice collisional fragmentation requires a large separation of vertical velocities of ice particles to enhance kinetic energy of their collision. The most likely candidates for this process are lightly and heavily rimed ice particles. The formation of graupel usually occurs in mixed-phase convective regions. Whether diffusionally grown ice particles may get fragmented colliding with each other remains unclear.

The theoretical analysis of the thermal shock fragmentation (King and Fletcher, 1976a) suggests that it requires precipitation-sized drops and temperatures lower than

mechanism. Theoretical and in situ observational works were not counted. Note that some publications were not cited in this work. 
Droplet fragmentation during freezing

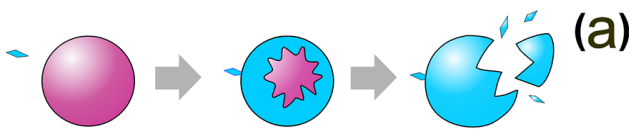

Splintering during riming (Hallett-Mossop process)

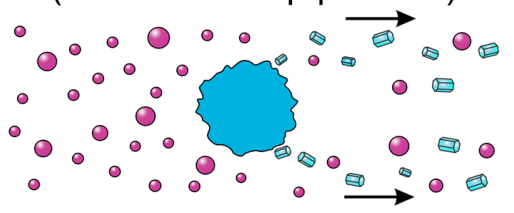

(b)

Fragmentation during ice-ice collision
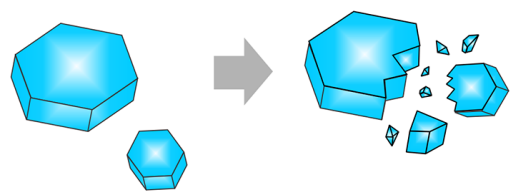

Ice fragmentation during thermal shock

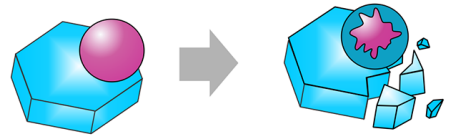

(d)

Fragmentation during sublimation

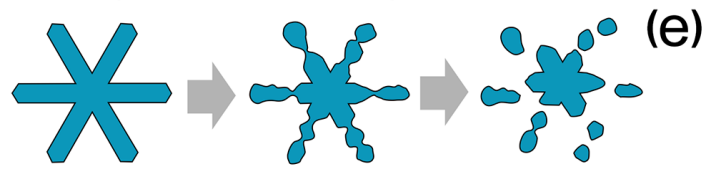

Activation of INPs in transient supersaturation

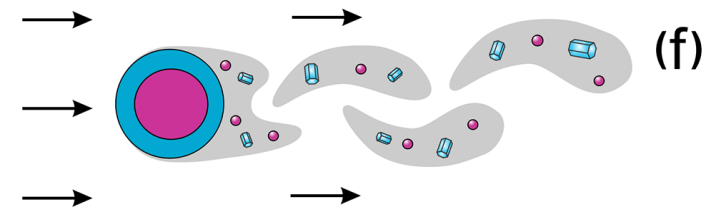

Figure 16. A conceptual diagram summarizing six SIP mechanisms: (a) fragmentation droplets during freezing, (b) rime splintering (HallettMossop process), (c) fragmentation of ice particles during ice-ice collision, (d) fragmentation of ice particles during thermal shock caused by a freezing drop attached to their surfaces, (e) fragmentation of ice particles during their sublimation, and (f) activation of supersaturationsensitive INPs in the transient supersaturation formed around freezing drops or wet graupel/hailstones. Blue color refers to ice phase and red color to liquid phase.

$-10^{\circ} \mathrm{C}$. Such conditions would be relevant for mixed-phase convective cloud regions where large drops could be transported by a vertical updraft to levels with low temperatures.

Activation of SIP due to the fragmentation of sublimating ice requires spatial proximity of undersaturated and supersaturated cloud regions. In this case, secondary ice particles formed in the undersaturated cloud regions can be rapidly transported into the supersaturated regions prior their sublimation. Such conditions may occur in cloud regions affected by entrainment and mixing with out-of-cloud dry air.

INP activation in transient supersaturation requires precipitation-sized drops and high supercooling. As indicated above, such conditions are typical for convective cloud regions.

Out of six SIP mechanisms, the droplet fragmentation during freezing and INP activation in transient supersaturation mechanisms appear to be primary candidates for initial production of secondary ice at the early stage of ice formation in convective clouds. The rest of the mechanisms require preexisting aged ice, and they may contribute to the ice concentration at later stages of cloud development.

It is worth mentioning that the possibility of additional SIP mechanisms beyond the purview of this paper (Fig. 16) remains unexplored. In this regard, studying the existence of other SIP mechanisms not described in this study is still on the agenda of SIP investigation (e.g., Knight, 2012).

When discussing the feasibility of SIP mechanisms, it is important to keep in mind well-documented observations of supercooled, persistent mixed-phase clouds with temporally stable low ice concentration $\left(<0.5-5 \mathrm{~L}^{-1}\right)$ (e.g., Korolev et al., 2017; McFarquhar et al., 2011; Shupe et al., 2006). In these clouds, seemingly satisfying some conditions required for SIP, no explosive enhancement of ice concentration was observed. Similar mixed-phase cloud environments with no SIP were also reproduced in laboratory experiments (Desai et al., 2019). These in situ and laboratory observations accentuate the importance of identifying the necessary and sufficient conditions required for the initiation of each of the SIP mechanisms.

Another unexplored possibility is related to enhancing the activation properties of typically ineffective primary INPs due to changing the local properties of the cloud environment. In Sect. 7, such activation of ineffective primary INPs occurred in the cloud environment modified by freezing drops (or wet hail and rimed ice particles) due to local increase of supersaturation. 


\subsection{The way forward}

The large discrepancies within the experimental results obtained by different research groups necessitate the development of laboratory setups that account for a variety of possible parameters that may be implicated in different SIP processes.

Because of the complexity involved in exploring SIP, obtaining consistent results from independent research groups is an important task for SIP studies. This would require consolidating efforts across the cloud physics community at the international level (Shaw et al., 2020). Laboratory investigations should go hand in hand with the development of theoretical descriptions of the SIP processes on a microscale level and in situ observations. This will create a foundation for physically based parameterizations for weather and climate models, which is the ultimate goal of all these efforts. 


\section{Appendix A: List of symbols and abbreviations}

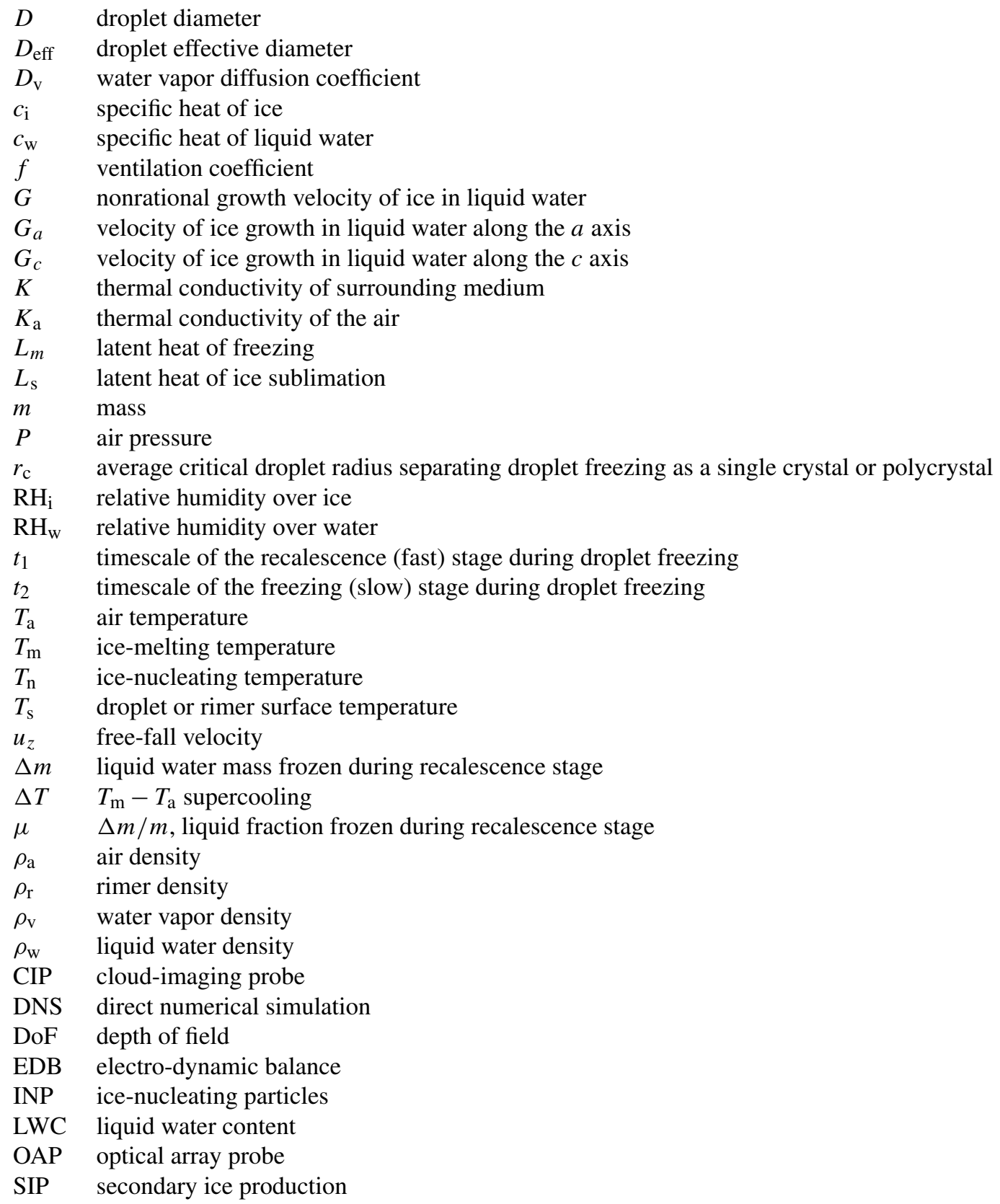


Data availability. All results described in this paper were obtained from open-source publications listed in the reference list.

Author contributions. AK drafted the manuscript. TL contributed Sect. 2 and co-wrote the paper.

Competing interests. The authors declare that they have no conflict of interest.

Acknowledgements. Special thanks are given to the ECCC librarians (Danny Chan and Derek Funston) for outstanding support in sourcing literature and provision of publications referenced in this study. The authors are grateful to Jim Dye (NCAR) and Paul Lawson (SPEC) for diligent and inspired discussions. The authors wish to express their gratitude to the open referees, Andy Heymsfield (NCAR) and Raymond Shaw (MTU), for their thorough reviews and valuable comments.

Financial support. Alexei Korolev's work was supported by Environment and Climate Change Canada (ECCC), Transport Canada (TC), and US Federal Aviation Administration (FAA) funds (FAAECCC Memorandum of Cooperation NAT-I-3444 (Appendix 11)). Thomas Leisner's work was supported by the Helmholtz Association under the Atmosphere and Climate Program (ATMO).

Review statement. This paper was edited by Daniel Knopf and reviewed by Raymond Shaw and Andrew Heymsfield.

\section{References}

Adkins, C. J.: The fragmentation and electrification of very small droplets, Q. J. Roy. Meteor. Soc., 86, 186, https://doi.org/10.1002/qj.49708636807, 1960.

Auer, A. H.: Observations of Ice Crystal Nucleation by Droplet Freezing in Natural Clouds, Journal de Recherches Atmosphériques, 4, 145-160, 1970.

Aufdermaur, A. N. and Mays, W. C.: Correlation between hailstone structure and growth conditions, in: Proceeding of the International Conference on Cloud Physics, Tokyo, 24 May-1 June 1965, 281-284, 1965.

Aufdermaur, A. N. and Johnson D. A.: Charge separation due to riming in an electric field, Q. J. Roy. Meteor. Soc., 98, 369-382, https://doi.org/10.1002/qj.49709841609, 1972.

Bacon, N. J., Swanson, B. D., Baker, M. B., and Davis, E. J.: Breakup of levitated frost particles, J. Geophys. Res.-Atmos., 103, 13763-13775, https://doi.org/10.1029/98JD01162, 1998.

Bader, M., Gloster, J., Brownscombe, J. L. Goldsmith, P.: The production of sub-micron ice fragments by water droplets freezing in free fall or on accretion upon an ice surface, Q. J. Roy. Meteor. Soc., 100, 420-426, https://doi.org/10.1002/qj.49710042513, 1974.
Baker, B. A.: On the Nucleation of Ice in Highly Supersaturated Regions of Clouds, J. Atmos. Sci., 48, 1904-1907, https://doi.org/10.1175/15200469(1991)048<1905:OTNOII>2.0.CO;2, 1991.

Bauerecker, S., Ulbig, P., Buch, V., Vrbka, L., and Jungwirth, P.: Monitoring ice nucleation in pure and salty water via high-speed imaging and computer simulations J. Phys. Chem. C, 112, 76317636, 2008.

Beard, K. V: Ice initiation in warm-base convective clouds: An assessment of microphysical mechanisms, Atmos. Res., 28, 125152, https://doi.org/10.1016/0169-8095(92)90024-5, 1992.

Bentley, W. A.: Study of frost and ice crystals, Mon. Weather Rev., 35, 512-516, 1907.

Bentley, W. A. and Humphreys, W. J.: Snow Crystals, Dover Publications, New York, 266 pp., 1962

Bigg, E. K.: The fragmentation of freezing water drop, Bull. l'Observatoire du Puy-de-Dôme, N3, 65-69, 1957.

Blanchard, D. G.: A verification of the Bally-Dorsey theory of spicule formation on sleet pellets, J. Meteorol., $\quad 8, \quad 268-269, \quad$ https://doi.org/10.1175/1520 0469(1951)008<0268:AVOTBD>2.0.CO;2, 1951.

Brewer, A. W. and Palmer, H. P.: Condensation Processes at Low Temperatures, and the Production of New Sublimation Nuclei by the Splintering of Ice, Nature, 164, 312-313, https://doi.org/10.1038/164312a0, 1949.

Brownscombe, J. L. and Thorndike, N. S. C.: Freezing and Shattering of Water Droplets in Free Fall, Nature, 220, 687-689, https://doi.org/10.1038/220687a0, 1968.

Cantrell, W. and Heymsfield, A. J.: Production of Ice in Tropospheric Clouds: A Review, B. Am. Meteorol. Soc., 86, 795-808, https://doi.org/10.1175/BAMS-86-6-795, 2005.

Cheng, R. J.: Water Drop Freezing: Ejection of Microdroplets, Science, 170, 1395-1396, https://doi.org/10.1126/science.170.3965.1395, 1970.

Chouippe, A., Krayer, M., Uhlmann, M., Dusek, J., Kiselev, A., and Leisner, T.: Heat and water vapor transfer in the wake of a falling ice sphere and its implication for secondary ice formation in clouds, New J. Phys., 21, 043043, https://doi.org/10.1088/13672630/ab0a94, 2019.

Choularton, T. W., Latham, J., and Mason, B. J.: A possible mechanism of ice splinter production during riming, Nature, 274, 791792, https://doi.org/10.1038/274791a0, 1978

Choularton, T. W., Griggs, D. J., Humood, B. Y., and Latham, J.: Laboratory studies of riming, and its relation to ice splinter production, Q. J. Roy. Meteor. Soc., 106, 367-374, https://doi.org/10.1002/qj.49710644809, 1980.

Cooper, W. A.: Cloud physics investigations by the University of Wyoming in HIPLEX 1977 Bureau of Reclamation Rep. No. AS119, Dept. of Atmospheric Science, University of Wyoming, Laramie, WY, 1977.

Cotton, W. R., Tripoli, G. J., Rauber, R. M., Mulvihill, E. A.: Numerical Simulation of the Effects of Varying Ice Crystal Nucleation Rates and Aggregation Processes on Orographic Snowfall, J. Clim. Appl. Meteorol., 25, 1658-1680, https://doi.org/10.1175/15200450(1986)025<1658:NSOTEO>2.0.CO;2, 1986.

Crawford, I., Bower, K. N., Choularton, T. W., Dearden, C., Crosier, J., Westbrook, C., Capes, G., Coe, H., Connolly, P. J., Dorsey, J. R., Gallagher, M. W., Williams, P., Trembath, J., Cui, Z., 
and Blyth, A.: Ice formation and development in aged, wintertime cumulus over the UK: observations and modelling, Atmos. Chem. Phys., 12, 4963-4985, https://doi.org/10.5194/acp12-4963-2012, 2012.

Crosier, J., Bower, K. N., Choularton, T. W., Westbrook, C. D., Connolly, P. J., Cui, Z. Q., Crawford, I. P., Capes, G. L., Coe, H., Dorsey, J. R., Williams, P. I., Illingworth, A. J., Gallagher, M. W., and Blyth, A. M.: Observations of ice multiplication in a weakly convective cell embedded in supercooled mid-level stratus, Atmos. Chem. Phys., 11, 257-273, https://doi.org/10.5194/acp-11257-2011, 2011.

Crosier, J., Choularton, T. W., Westbrook, C. D., Blyth, A. M., Bower, K. N., Connolly, P. J., Dearden, C., Gallagher, M. W., Cui, Z., and Nicol, J. C.: Microphysical properties of cold frontal rainbands, Q. J. Roy. Meteor. Soc., 140, 1257-1268, https://doi.org/10.1002/qj.2206, 2014.

Desai, N., Chandrakar, K. K., Kinney, G., Cantrell, W., and Shaw, R. A.: Aerosol-mediated glaciation of mixed-phase clouds: Steadystate laboratory measurements. Geophys. Res. Lett., 46, 91549162. https://doi.org/10.1029/2019GL083503, 2019.

Dong, Y. Y. and Hallett, J.: Droplet accretion during rime growth and the formation of secondary ice crystals, Q. J. Roy. Meteor. Soc., 115, 127-142, https://doi.org/10.1002/qj.49711548507, 1989.

Dong, Y. Y., Oraltay, R. G., and Hallett, J.: Ice particle generation during evaporation, Atmos. Res., 32, 45-53, https://doi.org/10.1016/0169-8095(94)90050-7, 1994.

Dorsey, N. E.: The Freezing of Supercooled Water, T. Am. Philos. Soc., 38, 247-328, available at: http://www.jstor.org/stable/ 1005602 (last access: October 2020), 1948.

Dudetski, V. and Sidorov, I. : About structure of water droplets freezing under different conditions, Journal of Russian Physical and Chemical Society, 43, 340-343, 1911.

Dye, J. E. and Hobbs, P. V.: The Influence of Environmental Parameters on the Freezing and Fragmentation of Suspended Water Drops, J. Atmos. Sci., 25, 82-96, https://doi.org/10.1175/15200469(1968)025<0082:TIOEPO>2.0.CO;2, 1968.

Emersic, C. and Connolly, P. J.: Microscopic observations of riming on an ice surface using high speed video, Atmos. Res., 185, 6572, https://doi.org/10.1016/j.atmosres.2016.10.014, 2017.

Feuillebois, F., Lasek, A., Creismeas, P., Pigeonneau, F., and Szaniawski, A.: Freezing of a subcooled liquid droplet, J. Colloid Interf. Sci., 169, 90-102. https://doi.org/10.1006/jcis.1995.1010, 1995.

Field, P. R., Wood, R., Brown, P. R. A., Kaye, P. H., Hirst, E., Greenaway, R., and Smith, J. A.: Ice Particle Interarrival Times Measured with a Fast FSSP, J. Atmos. Ocean. Tech., 20, 249-261, https://doi.org/10.1175/15200426(2003)020<0249:IPITMW>2.0.CO;2, 2003.

Field, P. R., Heymsfield, A. J., and Bansemer, A.: Shattering and Particle Interarrival Times Measured by Optical Array Probes in Ice Clouds, J. Atmos. Ocean. Tech., 23, 1357-1371, https://doi.org/10.1175/JTECH1922.1, 2006.

Field, P. R., Lawson, R. P., Brown, P. R. A., Lloyd, G., Westbrook, C., Moisseev, D., Miltenberger, A., Nenes, A., Blyth, A., Choularton, T., Connolly, P., Bühl, J., Crosier, J., Cui, Z., Dearden, C., DeMott, P., Flossmann, A. I., Heymsfield, A. J., Huang, Y. H., Kalesse, H., Kanji, Z. A., Korolev, A., Kirchgaessner, A., Lasher-Trapp, S., Leisner, T., McFarquhar, G., Phillips, V., Stith,
J., and Sullivan, S.: Secondary Ice Production - current state of the science and recommendations for the future, Meteor. Mon., 58, 7.1-7.20, https://doi.org/10.1175/AMSMONOGRAPHS-D16-0014.1, 2017.

Findeisen, W.: Über die Entstehung der Gewitterelek-trizität [On the origin of lightning electricity], Meteorol. Z., 6, 201-221, 1940.

Findeisen, W. and Findeisen, E.: Untersuchungen über die Eissplitterbildung an Reifschichten (Eio Beitrag zur Frage der Ents tebung der Gewitterelekfrizität und zur Mikrostruktur der Cumulonirnben) [Investigations on the ice splinters formation on rime layers (A contribution to the problem of the origin of storm electricity and to the microstructure of cumulonimbus], Meteorol. Z., 60, 145-154, 1943.

Foster, T. and Hallett, J.: A laboratory investigation of the influence of liquid water content on the temperature dependence of secondary ice crystal production during soft hail growth, in: Am. Met. Soc. Cloud Physics Conference, Chicago, 15-18 November 1982, 123-126, 1982.

Fukuta, N. and Lee, H. J.: A Numerical Study of the Supersaturation Field around Growing Graupel, J. Atmos. Sci., 43, 1833-1843, https://doi.org/10.1175/15200469(1986)043<1833:ANSOTS>2.0.CO;2, 1986.

Furukawa, Y. and Shimada, W.: Three-dimensional pattern formation duringgrowth of ice dendrites-its relation to universal law of dendritic growth, J. Cryst. Growth, 128, 234-239, 1993.

Gagin, A.: Effect of supersaturation on the ice crystal production by natural aerosols, Journal de Recherches Atmosphériques, 6, 175-185, 1972.

Gagin, A. and Nozyce, N.: The nucleation of ice crystals during the freezing of large supercooled drops, Journal de Recherches Atmosphériques, 18, 119-129, 1984.

Gardiner, B. A. and Hallett, J.: Degradation of InCloud Forward Scattering Spectrometer Probe Measurements in the Presence of Ice Particles, J. Atmos. Ocean. Tech., 2, 171-180, https://doi.org/10.1175/15200426(1985)002<0171:DOICFS>2.0.CO;2, 1985.

Gayet, J.-F., Febvre, G., and Larsen, H.: The Reliability of the PMS FSSP in the Presence of Small Ice Crystals, J. Atmos. Ocean. Tech., 13, 1300-1310, https://doi.org/10.1175/15200426(1996)013<1300:TROTPF>2.0.CO;2, 1996.

Gold, L. W.: Crack formation in ice plates by thermal shock, Can. J. Phys., 4, 1712-1728, https://doi.org/10.1139/p63-172, 1963.

Griggs, D. and Choularton, T.: Freezing modes of riming drops with application to ice splinter production, Q. J. Roy. Meteor. Soc., 109, 243-253, https://doi.org/10.1002/qj.49710945912, 1983.

Gupta, S. C. and Arora, P. R.: Analytical and numerical solutions of inward spherical solidification of a superheated melt with radiative-convective heat transfer and density jump at freezing front, Heat Mass Transfer, 27, 377-384, https://doi.org/10.1007/BF01600027, 1992.

Hallett, J.: Crystal Growth and the Formation of Spikes in the Surface of Supercooled Water, J. Glaciol., 3, 698-704, https://doi.org/10.3189/S0022143000017998, 1960.

Hallett, J.: Discussion of Douglas' paper, Meteor. Mon., 5, 18-170, 1963.

Hallett, J.: Experimental Studies of the Crystallization of Supercooled Water, J. Atmos. 
Sci., 21, 671-682, https://doi.org/10.1175/15200469(1964)021<0671:ESOTCO>2.0.CO;2, 1964.

Hallett, J. and Mossop, S. C.: Production of secondary ice particles during the riming process, Nature, 249, 26-28, https://doi.org/10.1038/249026a0, 1974.

Hallett, J., Sax, R. I., Lamb, D., and Murty, A. S. R.: Aircraft measurements of ice in Florida cumuli, Q. J. Roy. Meteor. Soc., 104, 631-651, https://doi.org/10.1002/qj.49710444108, 1978.

Heymsfield, A. and Willis, P.: Cloud Conditions Favoring Secondary Ice Particle Production in Tropical Maritime Convection, J. Atmos. Sci., 71, 4500-4526, https://doi.org/10.1175/JAS-D14-0093.1, 2014.

Heymsfield, A. J.: On measurements of small ice particles in clouds, Geophys. Res. Lett., 34, L23812, https://doi.org/10.1029/2007GL030951, 2007.

Heymsfield, A. J. and Mossop, S. C.: Temperature dependence of secondary ice crystal production during soft hail growth by riming, Q. J. Roy. Meteor. Soc., 110, 765-770, https://doi.org/10.1002/qj.49711046512, 1984.

Hindmarsh, J. P., Russell, A. B., and Chen, X. D.: Experimental and numerical analysis of the temperature transition of a suspended freezing water droplet, Int. J. Heat Mass Tran., 46, 1199-1213, https://doi.org/10.1016/S0017-9310(02)00399-X, 2003.

Hindmarsh, J. P., Wilson, D. I., and Johns, M. L.: Using magnetic resonance to validate predictions of the solid fraction formed during recalescence of freezing drops, Int. J. Heat Mass Tran., 48, 1017-1021, https://doi.org/10.1016/j.ijheatmasstransfer.2004.09.028, 2005.

Hobbs, P. V: Ice Multiplication in Clouds, J. Atmos. Sci., 26, 315-318, https://doi.org/10.1175/15200469(1969)026<0315:IMIC>2.0.CO;2, 1969.

Hobbs, P. V.: Microdroplets and Water Drop Freezing, Science, 173, 849, https://doi.org/10.1126/science.173.3999.849, 1971.

Hobbs, P. V. and Alkezweeny, A. J.: The Fragmentation of Freezing Water Droplets in Free Fall, J. Atmos. Sci., 25, 881-888, https://doi.org/10.1175/15200469(1968)025<0881:TFOFWD>2.0.CO;2, 1968.

Hobbs, P. V and Burrows, D. A.: The Electrification of an Ice Sphere Moving through Natural Clouds, J. Atmos. Sci., 23, 757-763, https://doi.org/10.1175/15200469(1966)023<0757:TEOAIS>2.0.CO;2, 1966.

Hobbs, P. V. and Farber, R.: Fragmentation of ice particles in clouds, Journal de Recherches Atmosphériques, 6, 245-258, 1972.

Hobbs, P. V. and Rangno, A. L.: Ice Particle Concentrations in Clouds, J. Atmos. Sci., 42, 2523-2549, https://doi.org/10.1175/15200469(1985)042<2523:IPCIC>2.0.CO;2, 1985.

Hobbs, P. V. and Rangno, A. L.: Rapid Development of High Ice Particle Concentrations in Small Polar Maritime Cumuliform Clouds, J. Atmos. Sci., 47, 2710-2722, https://doi.org/10.1175/15200469(1990)047<2710:RDOHIP>2.0.CO;2, 1989.

Iwabuchi, T. and Magono, C.: A Laboratory Experiment on the Freezing Electrification of Freely Falling Water Droplets, J. Meteorol. Soc. Jpn., 53, 393-401, https://doi.org/10.2151/jmsj1965.53.6_393, 1975.

Jackson, R. C., McFarquhar, G. M., Stith, J., Beals, M., Shaw, R., Jensen, J., Fugal, J., and Korolev, A.: An assessment of the impact of anti-shattering tips and artifact removal techniques on cloud ice size distributions measured by the 2D Cloud Probe, J. Atmos. Ocean. Tech., 31, 2567-2590, https://doi.org/10.1175/JTECH-D-13-00239.1, 2015

Jensen, E. J., Lawson, P., Baker, B., Pilson, B., Mo, Q., Heymsfield, A. J., Bansemer, A., Bui, T. P., McGill, M., Hlavka, D., Heymsfield, G., Platnick, S., Arnold, G. T., and Tanelli, S.: On the importance of small ice crystals in tropical anvil cirrus, Atmos. Chem. Phys., 9, 5519-5537, https://doi.org/10.5194/acp-95519-2009, 2009.

Jiusto, J. E. and Weickmann, H. K.: types of snowfall, B. Am. Meteorol. Soc., 54, 1148-1162, https://doi.org/10.1175/1520 0477(1973)054<1148:TOS>2.0.CO;2, 1973.

Johnson, D. A. and Hallett, J.: Freezing and shattering of supercooled water drops, Q. J. Roy. Meteor. Soc., 94, 468-482, https://doi.org/10.1002/qj.49709440204, 1968.

Kachurin, L. G. and Bekryaev, V. I.: Investigation of the electrification of crystallizing water, Dokl. Akad. Nauk. SSSR, 130, 57-60, 1960.

Kallungal, J. P. and Barduhn, A. J.: Growth rate of an ice crystal in subcooled pure water, AiChe J., 23, 294-303, https://doi.org/10.1002/aic.690230312, 1977.

Kanji, Z. A., Ladino, L. A., Wex, H., Boose, Y., BurkertKohn, M., Cziczo, D. J., and Krämer, M.: Overview of Ice Nucleating Particles, Meteor. Mon., 58, 1.1-1.33, https://doi.org/10.1175/AMSMONOGRAPHS-D-16-0006.1, 2017.

Keinert, A., Spannagel, D., Leisner, T., and Kiselev, A.: Secondary ice production upon freezing of freely falling drizzle droplets, J. Atmos. Sci., 77, 2959-2967, https://doi.org/10.1175/JAS-D-200081.1, 2020.

Keppas, S. C., Crosier, J., Choularton, T. W., and Bower, K. N.: Ice lollies: An ice particle generated in supercooled conveyor belts, Geophys. Res. Lett., 44, 5222-5230, https://doi.org/10.1002/2017GL073441, 2017.

Kikuchi, K. and Uyeda, H.: On Snow Crystals of Spatial Dendritic Type, J. Meteorol. Soc. Jpn., 57, 282-287, https://doi.org/10.2151/jmsj1965.57.3_282, 1979.

King, W. D.: Freezing Rates of Water Droplets, J. Atmos. Sci., 32, 403-408, https://doi.org/10.1175/1520 0469(1975)032<0403:FROWD>2.0.CO;2, 1975

King, W. D. and Fletcher, N. H.: Pressures and stresses in freezing water drops, J. Phys. D Appl. Phys., 6, 2157-2173, https://doi.org/10.1088/0022-3727/6/18/302, 1973.

King, W. D. and Fletcher, N. H.: Thermal Shock as an Ice Multiplication Mechanism. Part I. Theory, J. Atmos. Sci., 33, 85-96, https://doi.org/10.1175/15200469(1976)033<0085:TSAAIM>2.0.CO;2, 1976a.

King, W. D. and Fletcher, N. H.: Thermal Shock as an Ice Multiplication Mechanism. Part II. Experimental, J. Atmos. Sci., 33, 97-102, https://doi.org/10.1175/15200469(1976)033<0097:tsaaim>2.0.co;2, 1976b.

Knight, C. A.: Ice Growth from the Vapor at $-5^{\circ} \mathrm{C}$, J. Atmos. Sci., 69, 2031-2040, https://doi.org/10.1175/JAS-D-11-0287.1, 2012.

Knollenberg, R. G.: Techniques for probing cloud microstructure, in: Clouds their Formation, Optical Properties, and Effects, edited by: Hobbs, P. V and Deepak, A., Academic Press, New York, 15-91,1981. 
Koenig, L. R.: The Glaciating Behavior of Small Cumulonimbus Clouds, J. Atmos. Sci., 20, 29-47, https://doi.org/10.1175/15200469(1963)020<0029:TGBOSC>2.0.CO;2, 1963.

Koenig, L. R.: Drop Freezing Through Drop Breakup, J. Atmos. Sci., 22, 448-451, https://doi.org/10.1175/15200469(1965)022<0448:DFTDB>2.0.CO;2, 1965.

Kolomeychuk, R. J., McKay, D. C., and Iribarne, J. V.: The Fragmentation and Electrification of Freezing Drops, J. Atmos. Sci., 32, 974-979, https://doi.org/10.1175/15200469(1975)032<0974:TFAEOF>2.0.CO;2, 1975.

Korolev, A. and Field, P. R.: Assessment of the performance of the inter-arrival time algorithm to identify ice shattering artifacts in cloud particle probe measurements, Atmos. Meas. Tech., 8, 761777, https://doi.org/10.5194/amt-8-761-2015, 2015.

Korolev, A., Heckman, I., Wolde, M., Ackerman, A. S., Fridlind, A. M., Ladino, L. A., Lawson, R. P., Milbrandt, J., and Williams, E.: A new look at the environmental conditions favorable to secondary ice production, Atmos. Chem. Phys., 20, 1391-1429, https://doi.org/10.5194/acp-20-1391-2020, 2020.

Korolev, A. V.: Reconstruction of the Sizes of Spherical Particles from Their Shadow Images. Part I: Theoretical Considerations, J. Atmos. Ocean. Tech., 24, 376-389, https://doi.org/10.1175/JTECH1980.1, 2007.

Korolev, A. V and Isaac, G. A.: Observations of sublimating ice particles in clouds, in: Proceedings of the 14th International Conference on Clouds and Precipitation, 19-23 July, Bologna, Italy , 808-811, 2004.

Korolev, A. V. and Isaac, G. A.: Shattering during sampling by OAPs and HVPS. Part 1: Snow particles, J. Atmos. Ocean. Tech., 22, 528-542, https://doi.org/10.1175/JTECH1720.1, 2005.

Korolev, A. V., Bailey, M. P., Hallett, J., and Isaac, G. A.: Laboratory and in situ observation of deposition growth of frozen drops, J. Appl. Meteorol., 43, 612-622, https://doi.org/10.1175/15200450(2004)043<0612:LAISOO>2.0.CO;2, 2004.

Korolev, A. V., Emery, E. F., Strapp, J. W., Cober, S. G., Isaac, G. A., Wasey, M., and Marcotte, D.: Small Ice Particles in Tropospheric Clouds: Fact or Artifact? Airborne Icing Instrumentation Evaluation Experiment, B. Am. Meteorol. Soc., 92, 967-973, https://doi.org/10.1175/2010BAMS3141.1, 2011.

Korolev, A. V., Emery, E., and Creelman, K.: Modification and Tests of Particle Probe Tips to Mitigate Effects of Ice Shattering, J. Atmos. Ocean. Tech., 30, 690-708, https://doi.org/10.1175/JTECH-D-12-00142.1, 2013a.

Korolev, A. V, Emery, E. F., Strapp, J. W., Cober, S. G., and Isaac, G. A.: Quantification of the Effects of Shattering on Airborne Ice Particle Measurements, J. Atmos. Ocean. Tech., 30, 2527-2553, https://doi.org/10.1175/JTECH-D-13-00115.1, $2013 \mathrm{~b}$.

Korolev, A. V. , McFarquhar, G., Field, P. R., Franklin, C., Lawson, P., Wang, Z., Williams, E., Abel, S. J., Axisa, D., Borrmann, S., Crosier, J., Fugal, J., Krämer, M., Lohmann, U., Schlenczek, O., Schnaiter, M., and Wendisch, M.: MixedPhase Clouds: Progress and Challenges, Meteor. Mon., 58, 5.1-5.50, https://doi.org/10.1175/AMSMONOGRAPHS-D-170001.1, 2017.

Krayer, M., Chouippe, A., Uhlmann, M., Dušek, J., and Leisner, T.: On the ice-nucleating potential of warm hydrometeors in mixed-phase clouds, Atmos. Chem. Phys. Discuss., https://doi.org/10.5194/acp-2020-136, in review, 2020.
Kumai, M. and Itagaki, K.: Cinematographic study of ice crystal formation in water, Journal of the Faculty of Science, Hokkaido University, Ser. 2, 4, 235-46, 1953.

Ladino, L. A., Korolev, A., Heckman, I., Wolde, M., Fridlind, A. M., and Ackerman, A. S.: On the role of ice-nucleating aerosol in the formation of ice particles in tropical mesoscale convective systems, Geophys. Res. Lett., 44, 1574-1582, https://doi.org/10.1002/2016GL072455, 2017.

Langer, J. S., Muller-Krumbhaar, H.: Theory of dendritic growth-I. Elements of a stability analysis, Acta Metall. Mater., 26, 1681-1687, https://doi.org/10.1016/0001-6160(78)90078-0, 1978.

Langham, E. J. and Mason, B. J.: Heterogeneous and homogeneous nucleation of supercooled water, P. Roy. Soc. Lond. A Mat., A247, 493-504, 1958.

Langmuir, I.: The Production of Rain by a Chain Reaction in Cumulus Clouds at Temperatures above Freezing, J. Atmos. Sci., 5, 175-192, https://doi.org/10.1175/15200469(1948)005<0175:TPORBA>2.0.CO;2, 1948.

Lasher-Trapp, S., Leon, D. C., DeMott, P. J., Villanueva-Birriel, C. M., Johnson, A. V, Moser, D. H., Tully, C. S., and Wu, W.: A Multisensor Investigation of Rime Splintering in Tropical Maritime Cumuli, J. Atmos. Sci., 73, 2547-2564, https://doi.org/10.1175/JAS-D-15-0285.1, 2016.

Latham, J. and Mason, B. J.: Generation of electric charge associated with the formation of soft hail in thunderclouds, P. Roy. Soc. Lond. A Mat., 260, 237-249, https://doi.org/10.1098/rspa.1961.0052, 1961.

Lauber, A., Kiselev, A., Pander, T., Handmann, P., and Leisner, T.: Secondary Ice Formation during Freezing of Levitated Droplets, J. Atmos. Sci., 75, 2815-2826, https://doi.org/10.1175/JAS-D18-0052.1, 2018.

Lawson, R. P.: Effects of ice particles shattering on the 2D-S probe, Atmos. Meas. Tech., 4, 1361-1381, https://doi.org/10.5194/amt4-1361-2011, 2011.

Lawson, R. P., Woods, S., and Morrison, H.: The microphysics of ice and precipitation development in tropical cumulus clouds, J. Atmos. Sci., 72, 2429-2445, https://doi.org/10.1175/JAS-D-140274.1, 2015

Lawson, P., Gurganus, C., Woods, S., and Bruintjes, R.: Aircraft Observations of Cumulus Microphysics Ranging from the Tropics to Midlatitudes: Implications for a "New" Secondary Ice Process, J. Atmos. Sci., 74, 2899-2920, https://doi.org/10.1175/JASD-17-0033.1, 2017.

Lindenmeyer, C. S., Orrok, G. T., Jackson K. A., and Chalmers, B.: Rate of growth of ice crystals in supercooled water, J. Chem. Phys., 27, 822-823, 1959.

Lloyd, G., Choularton, T. W., Bower, K. N., Gallagher, M. W., Connolly, P. J., Flynn, M., Farrington, R., Crosier, J., Schlenczek, O., Fugal, J., and Henneberger, J.: The origins of ice crystals measured in mixed-phase clouds at the highalpine site Jungfraujoch, Atmos. Chem. Phys., 15, 12953-12969, https://doi.org/10.5194/acp-15-12953-2015, 2015.

López, M. L. and Ávila, E. E.: Deformations of frozen droplets formed at $-40^{\circ} \mathrm{C}$, Geophys. Res. Lett., 39, L01805, https://doi.org/10.1029/2011GL050185, 2012.

Ludlam, F. H.: The heat economy of a rimed cylinder, Q. J. Roy. Meteor. Soc., 77, 663-666, https://doi.org/10.1002/qj.49707733410, 1951. 
Macklin, W. C.: The Production of Ice Splinters During Riming, Nubila, 3, 30-33, 1960.

Macklin, W. C. and Payne, G.: A theoretical study of the ice accretion process, Q. J. Roy. Meteor. Soc., 93, 195-214. https://doi.org/10.1002/qj.49709339606, 1967.

Macklin, W. C. and Payne, G. S.: Growth velocities of ice in supercooled water and aqueous sucrose solutions, Philos. Mag., 17, 83-87, https://doi.org/10.1080/14786436808218182, 1968.

Macklin, W. C. and Payne, G. S.: The spreading of accreted droplets, Q. J. Roy. Meteor. Soc., 95, 724-730, https://doi.org/10.1002/qj.49709540606, 1969.

Macklin, W. C. and Ryan, B. F.: The Structure of Ice Grown in Bulk Supercooled Water, J. Atmos. Sci., 22, 452-459, https://doi.org/10.1175/15200469(1965)022<0452:TSOIGI>2.0.CO;2, 1965.

Macklin, W. C. and Ryan, B. F.: Habits of ice grown in supercooled water and aqueous solutions, Philos. Mag., 14, 847-860, https://doi.org/10.1080/14786436608211977, 1966.

Macklin, W. C. and Ryan, B. F.: Growth velocities of ice in supercooled water and aqueous sucrose solutions, Philos. Mag., 17, 83-87, https://doi.org/10.1080/14786436808218182, 1968.

Magono, C. and Aburakawa, H.: Experimental Studies of Snow Crystals of plane type with Spatial Branches, Journal of the Faculty of Science, Hokkaido University, Ser. 7, Geophysics, 3, 8597, available at: http://hdl.handle.net/2115/8680 (last access: October 2020), 1969.

Malkina, A. D. and Zak, E. G.: Mechanism of freezing of liquid droplets, Transactions of the Central Aerological Observatory (Trudi TsAO), 9, 61-75, 1952.

Mason, B. J. and Maybank, J.: The fragmentation and electrification of freezing water drops, Q. J. Roy. Meteor. Soc., 86, 176-185, https://doi.org/10.1002/qj.49708636806, 1960.

McFarquhar, G. M., Um, J., Freer, M., Baumgardner, D., Kok, G. L., and Mace, G.: Importance of small ice crystals to cirrus properties: Observations from the Tropical Warm Pool International Cloud Experiment (TWP-ICE), Geophys. Res. Lett., 34, L13803, https://doi.org/10.1029/2007GL029865, 2007.

McFarquhar, G. M., Ghan, S., Verlinde, J., Korolev, A., Strapp, J. W., Schmid, B., Tomlinson, J. M., Wolde, M., Brooks, S. D., Cziczo, D., Dubey, M. K., Fan, J., Flynn, C. R., Gultepe, I., Hubbe, J., Gilles, M. K., Laskin, A., Lawson, P., Leaitch, W. R., Liu, P., Liu, X., Lubin, D., Mazzoleni, C., Macdonald, A.M., Moffet, R. C., Morrison, H., Ovchinnikov, M., Shupe, M. D., Turner, D. D., Xie, S., Zelenyuk, A., Bae, K., Freer, M., Glen, A..: Indirect and Semi-Direct Aerosol Campaign: The impact of Arctic aerosols on clouds, B. Amer. Meteor. Soc., 92, 183-201, https://doi.org/10.1175/2010BAMS2935.1, 2011.

Meyers, M. P., Walko, R. L., Harrington, J. Y., and Cotton, W. R.: New RAMS cloud microphysics parameterization. Part II: The two-moment scheme, Atmos. Res., 45, 3-39, https://doi.org/10.1016/S0169-8095(97)00018-5, 1997.

Mossop, S. C.: Concentrations of Ice Crystals in Clouds, B. Amer. Meteorol. Soc., 51, 474-479, https://doi.org/10.1175/15200477(1970)051<0474:COICIC>2.0.CO;2, 1970.

Mossop, S. C.: Production of secondary ice particles during the growth of graupel by riming, Q. J. Roy. Meteor. Soc., 102, 45-57, https://doi.org/10.1002/qj.49710243104, 1976.

Mossop, S. C.: Some Factors Governing Ice Particle Multiplication in Cumulus Clouds, J. Atmos.
Sci., 35, 2033-2037, https://doi.org/10.1175/1520 0469(1978)035<2033:SFGIPM>2.0.CO;2, 1978.

Mossop, S. C.: The mechanism of ice splinter production during riming, Geoph. Res. Lett., 7, 167-169, https://doi.org/10.1029/GL007i002p00167, 1980.

Mossop, S. C.: The Origin and Concentration of Ice Crystals in Clouds, B. Amer. Meteorol. Soc., $\quad 66, \quad 264-273, \quad$ https://doi.org/10.1175/15200477(1985)066<0264:TOACOI>2.0.CO;2, 1985a.

Mossop, S. C.: Secondary ice particle production during rime growth: The effect of drop size distribution and rimer velocity, Q. J. Roy. Meteor. Soc., 111, 1113-1124, https://doi.org/10.1002/qj.49711147012, 1985b.

Mossop, S. C. and Hallett, J.: Ice Crystal Concentration in Cumulus Clouds: Influence of the Drop Spectrum, Science, 186, 632-634, https://doi.org/10.1126/science.186.4164.632, 1974.

Mossop, S. C., Ono, A., and Heffernan, K. J.: Studies of ice crystal in natural clouds, Journal de Recherches Atmosphériques, 3, 4564, 1964.

Mossop, S. C., Cottis, R. E., and Bartlett, B. M.: Ice crystal concentrations in cumulus and stratocumulus clouds, Q. J. Roy. Meteor. Soc., 98, 105-123, https://doi.org/10.1002/qj.49709841509, 1972.

Mossop, S. C., Brownscombe, J. L., and Collins, G. J.: The production of secondary ice particles during riming, Q. J. Roy. Meteor. Soc., 100, 427-436, https://doi.org/10.1002/qj.49710042514, 1974

Muchnik, V. M. and Rudko, J. S.: Peculiarities of freezing supercooled water drops, Transactions of Ukrainian Hydro Meteorological Institute (Trudi UkrNIGMI), 26, 64-73, 1961.

Muchnik, V. M. and Rudko, J. S.: Processes of cooling and freezing of water drops, Transactions of Ukrainian Hydro Meteorological Institute (Trudi UkrNIGMI), 31, 133-144, 1962.

Murray, W. A. and List, R.: Freezing of water drops, J. Glaciol., 11, 415-429, 1972

Nix, N. and Fukuta, N.: Nonsteady-State Kinetics of Droplet Growth in Cloud Physics, J. Atmos. Sci., 31, 1334-1343, https://doi.org/10.1175/15200469(1974)031<1334:NSKODG>2.0.CO;2, 1974.

Ohsaka, K., and Trinh, E. H.: Apparatus for measuringthe growth velocity of dendritic ice in undercooled water, J. Cryst. Growth, 194, 138-142, 1998.

Ono, A.: Some Aspects of the Natural Glaciation Processes in Relatively Warm Maritime Clouds, J. Meteorol. Soc. Jpn., 49A, 845858, https://doi.org/10.2151/jmsj1965.49A.0_845, 1971.

Ono, A.: Evidence on the nature of ice crystal multiplication processes in natural cloud, Journal de Recherches Atmosphériques, 6, 399-408, 1972.

Oraltay, R. G. and Hallett, J.: Evaporation and melting of ice crystals: A laboratory study, Atmos. Res., 24, 169-189, https://doi.org/10.1016/0169-8095(89)90044-6, 1989.

Pander, T.: Laboratory ice multiplication experiments in levitated microdroplets, PhD dissertation, University of Heidelberg, https://doi.org/10.11588/heidok.00018784, 2015.

Pena, J. A., de Pena, R. G., and Hosler, C. L.: Freezing of Water Droplets in Equilibrium with Different Gases, J. Atmos. Sci., 26, 309-314, https://doi.org/10.1175/15200469(1969)026<0309:FOWDIE>2.0.CO;2, 1969. 
Phillips, V. T. J., Patade, S., Gutierrez, J., and Bansemer, A.: Secondary Ice Production by Fragmentation of Freezing Drops: Formulation and Theory, J. Atmos. Sci., 75, 3031-3070, https://doi.org/10.1175/jas-d-17-0190.1, 2018.

Pitter, R. L. and Pruppacher, H. R.: A wind tunnel investigation of freezing of small water drops falling at terminal velocity in air, Q. J. Roy. Meteor. Soc., 99, 540-550, https://doi.org/10.1002/qj.49709942111, 1973.

Prabhakaran, P, Kinney, G., Cantrell, W., Shaw, R. A., and Bodenschatz, E.: High Supersaturation in the Wake of Falling Hydrometeors: Implications for Cloud Invigoration and Ice Nucleation, Geophys. Res. Lett., 47, e2020GL088055, https://doi.org/10.1029/2020GL088055, 2020.

Pruppacher, H. R.: On the growth of ice crystals in supercooled water and aqueous solution drops, Pure Appl. Geophys., 86, 186195, https://doi.org/10.1007/BF00874894, 1967a.

Pruppacher, H. R.: Growth Modes of Ice Crystals in Supercooled Water and Aqueous Solutions, J. Glaciol., 6, 651-662. https://doi.org/10.3189/S0022143000019924, $1967 \mathrm{~b}$.

Pruppacher, H. R. and Klett, J. D.: Microphysics of clouds and precipitation, Kluwer Academic Publishers, Dordrecht, 954 pp., 1997.

Pruppacher, H. R. and Schlamp, R. J.: A wind tunnel investigation on ice multiplication by freezing of waterdrops falling at terminal velocity in air, J. Geophys. Res., 80, 380-386, https://doi.org/10.1029/jc080i003p00380, 1975.

Puzanov, P. and Accuratov, V. I.: Towards formation mechanism of some types of hail, Gidrologia i Meteorologia, N6, 29-33, 1952.

Rangno, A. L.: Fragmentation of Freezing Drops in Shallow Maritime Frontal Clouds, J. Atmos. Sci., 65, 1455-1466, https://doi.org/10.1175/2007jas2295.1, 2008.

Reisner, J., Rasmussen, R. M., and Bruintjes, R. T.: Explicit forecasting of supercooled liquid water in winter storms using the MM5 mesoscale model, Q. J. Roy. Meteor. Soc., 124, 10711107, https://doi.org/10.1002/qj.49712454804, 1998.

Rosinski, J., Langer, G., and Nagamoto, C. T.: On the effect of microdroplets from the surface of a freezing water drop, J. Appl. Meteorol., 11, 405-406, 1972.

Rosinski, J., Nagamoto, C. T., and Kerrigan, T. C.: Heterogeneous nucleation of water and ice in the transient supersaturation field surrounding a freezing drop, Journal de Recherches Atmosphériques, 9, 107-117, 1975.

Saunders, C. P. R. and Hosseini, A. S.: A laboratory study of the effect of velocity on Hallett-Mossop ice crystal multiplication, Atmos. Res., 59, 3-14, https://doi.org/10.1016/S01698095(01)00106-5, 2001.

Schaefer, V. J.: Formation of Ice Crystals in Ordinary and Nuclei-Free Air, Ind. Eng. Chem., 44, 1300-1304, https://doi.org/10.1021/ie50510a033, 1952.

Schaefer, V. S.: Condensed Water in the Free Atmosphere in Air Colder than $-40 \mathrm{C}$, J. Appl. Meteor., $\quad 1, \quad 481-488, \quad$ https://doi.org/10.1175/15200450(1962)001<0481:CWITFA>2.0.CO;2, 1962.

Schaefer, V. J. and Cheng, R. J.: The production of ice crystal fragments by sublimation and electrification, Journal de Recherches Atmosphériques, 5, 5-10, 1971.

Schwarzenboeck, A., Shcherbakov, V., Lefevre, R., Gayet, J. F., Pointin, Y., and Duroure, C.: Indications for stellar-crystal fragmentation in Arctic clouds, Atmos. Res., 92, 220-228, https://doi.org/10.1016/j.atmosres.2008.10.002, 2009.

Shaw, R. A., Cantrell, W., Chen, C., Chuang, P., Donahue, N., Feingold, G., Kollias, P., Korolev, A., Kreidenweis, S., Krueger, S., Mellado J. P., Niedermeier, D., Xue, L.: CloudAerosol-Turbulence Interactions: Science Priorities and Concepts for a Large-Scale Laboratory Facility, B. Amer. Meteor. Soc., 101, E1026-E1035, https://doi.org/10.1175/BAMS-D-200009.1, 2020.

Shibkov, A. A., Golovin, Yu. I., Zheltov, M. A., Korolev, A. A., and Leonov, A. A.: Morphology diagram of nonequilibrium patterns of ice crystals growing in supercooled water, Physica A, 319, 65 $-79,2003$.

Shibkov, A. A., Zheltov, M.A., Korolev, A. A., Kazakov, A. A., Leonov, A. A.: Crossover from diffusion-limited to kineticslimited growth of ice crystals. J. Cryst. Growth, 285, 215-227, https://doi.org/10.1016/j.jcrysgro.2005.08.007, 2005

Shupe, M. D., Matrosov, S. Y., and Uttal, T.: Arctic mixed-phase cloud properties derived from surface-based sensors at SHEBA. J. Atmos. Sci., 63, 697-711, https://doi.org/10.1175/JAS3659.1, 2006.

Stith, J. L., Avallone, L. M., Bansemer, A., Basarab, B., Dorsi, S. W., Fuchs, B., Lawson, R. P., Rogers, D. C., Rutledge, S., and Toohey, D. W.: Ice particles in the upper anvil regions of midlatitude continental thunderstorms: the case for frozen-drop aggregates, Atmos. Chem. Phys., 14, 1973-1985, https://doi.org/10.5194/acp-14-1973-2014, 2014.

Stott, D. and Hutchinson, W. C. A.: The electrification of freezing water drops, Q. J. Roy. Meteor. Soc., 91, 80-86, https://doi.org/10.1002/qj.49709138711, 1965.

Tabakova, S., Feuillebois, F., and Radev S.: Freezing of a supercooled spherical droplet with mixed boundary conditions, Proc. Roy. Soc. A-Math. Phy., 466, 1117-1134, https://doi.org/10.1098/rspa.2009.0491, 2010.

Takahashi, C.: Deformations of Frozen Water Drops and Their Frequencies, J. Meteorol. Soc. Jpn., 53, 402-411, https://doi.org/10.2151/jmsj1965.53.6_402, 1975.

Takahashi, C.: Relation between the Deformation and the Crystalline Nature of Frozen Water Drops, J. Meteorol. Soc. Jpn., 54, 448-453, https://doi.org/10.2151/jmsj1965.54.6_448, 1976.

Takahashi, C. and Yamashita, A.: Deformation and Fragmentation of Freezing Water Drops in Free Fall, J. Meteorol. Soc. Jpn., 47, 431-436, https://doi.org/10.2151/jmsj1965.47.6_431, 1969.

Takahashi, C. and Yamashita, A.: Shattering of Frozen Water Drops in a Supercooled Cloud, J. Meteorol. Soc. Jpn., 48, 373-376, https://doi.org/10.2151/jmsj1965.48.4_373, 1970.

Takahashi, T.: High ice crystal production in winter cumuli over the Japan Sea, Geophys. Res. Lett., 20, 451-454, https://doi.org/10.1029/93GL00613, 1993.

Takahashi, T., Nagao, Y., and Kushiyama, Y.: Possible High Ice Particle Production during Graupel-Graupel Collisions, J. Atmos. Sci., 52, 4523-4527, 1995.

Tavakoli, F., Stephen, H., Davis, S. H., and Kavehpour, H.P.: Freezing of supercooled water drops on cold solid substrates: initiation and mechanism, J. Coat. Technol. Res., 12, 869-875, https://doi.org/10.1007/s11998-015-9693-0, 2015

Uyeda, H. and Kikuchi, K.: Freezing Experiment of Supercooled Water Droplets Frozen by Using Single Crystal Ice, J. Meteorol. 
Soc. Jpn., 56, 43-51, https://doi.org/10.2151/jmsj1965.56.1_43, 1978.

Vaillant de Guélis, T., Schwarzenböck, A., Shcherbakov, V., Gourbeyre, C., Laurent, B., Dupuy, R., Coutris, P., and Duroure, C.: Study of the diffraction pattern of cloud particles and the respective responses of optical array probes, Atmos. Meas. Tech., 12, 2513-2529, https://doi.org/10.5194/amt12-2513-2019, 2019.

Vardiman, L.: The Generation of Secondary Ice Particles in Clouds by Crystal-Crystal Collision, J. Atmos. Sci., 35, 2168-2180, https://doi.org/10.1175/15200469(1978)035<2168:TGOSIP>2.0.CO;2, 1978.

Vidaurre, G. and Hallett, J.: Particle Impact and Breakup in Aircraft Measurement, J. Atmos. Ocean. Tech., 26, 972-983, https://doi.org/10.1175/2008JTECHA1147.1, 2009.
Visagie, P. J.: Pressures Inside Freezing Water Drops, J. Glaciol., 8, 301-309, https://doi.org/10.3189/S0022143000031270, 1969.

Wildeman, S., Sterl, S., Sun, C., and Lohse, D.: Fast Dynamics of Water Droplets Freezing from the Outside In, Phys. Rev. Lett., 118, 84101, https://doi.org/10.1103/PhysRevLett.118.084101, 2017.

Yano, J.-I. and Phillips, V. T. J.: Ice-Ice Collisions: An Ice Multiplication Process in Atmospheric Clouds, J. Atmos. Sci., 68, 322-333, https://doi.org/10.1175/2010JAS3607.1, 2011.

Yano, J.-I., Phillips, V. T. J., and Kanawade, V.: Explosive ice multiplication by mechanical break-up in ice-ice collisions: a dynamical system-based study, Q. J. Roy. Meteor. Soc., 142, 867-879, https://doi.org/10.1002/qj.2687, 2016. 